\title{
TRUTHMAKING AND THE WORLD-TIME PARALLEL
}

\author{
By \\ Gareth Leniston-Lee
}

\begin{abstract}
A thesis
submitted to the Victoria University of Wellington in fulfilment of the requirements for the degree of Master of Arts in Philosophy
\end{abstract}

Victoria University of Wellington 


\section{Contents}

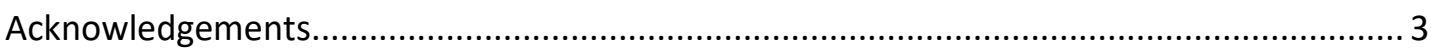

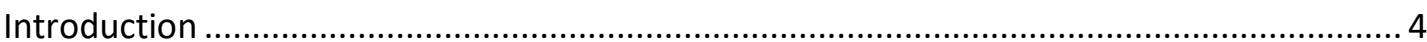

Chapter 1: Two Debates in Ontology and Semantics..................................................... 7

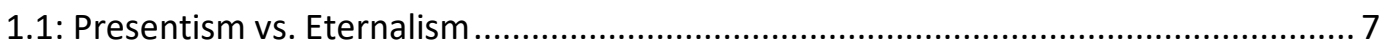

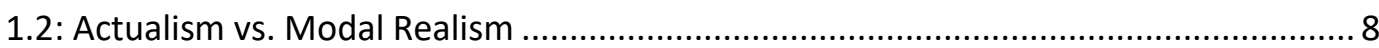

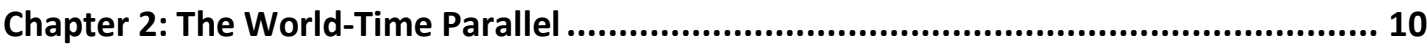

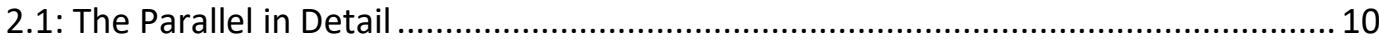

2.2: Illustrating the Parallel........................................................................................ 12

2.2.1: McTaggart's Argument for the Unreality of Time ......................................... 13

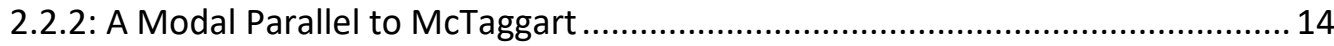

2.2.3: Forbes' Disanalogy between Actuality and Presence........................................ 16

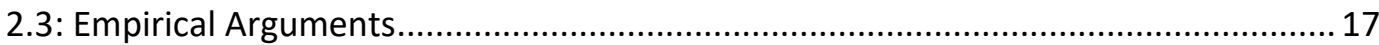

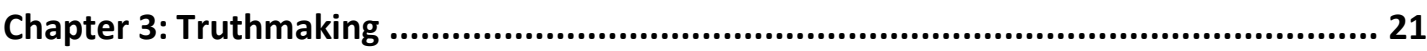

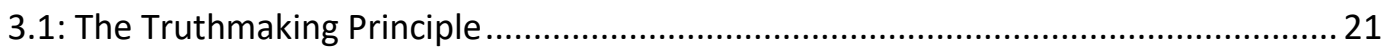

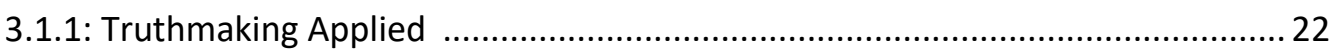

3.1.2: Maximalism and Negative Existentials ............................................................ 24

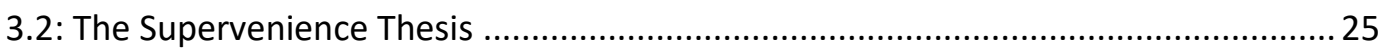

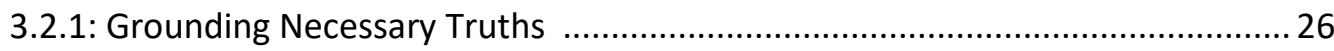

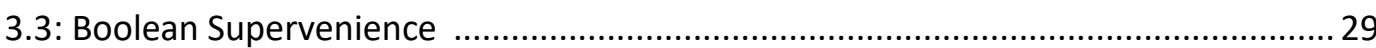

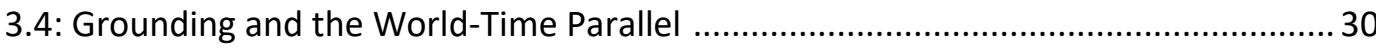

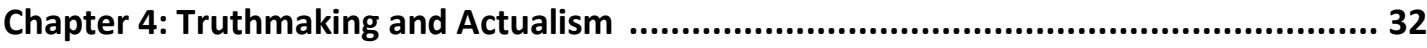

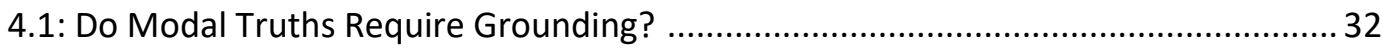

4.2: Is a Reductive Account of Modality Necessary? ...................................................... 32

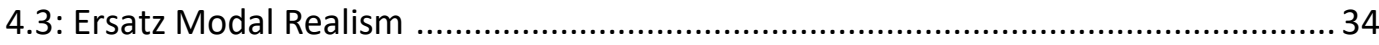

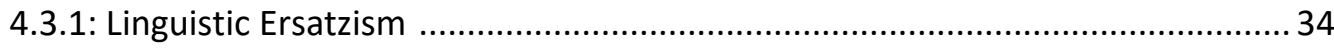

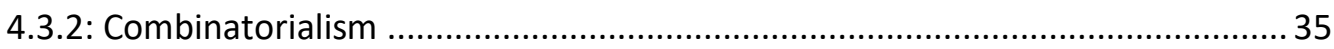

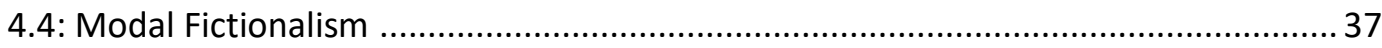

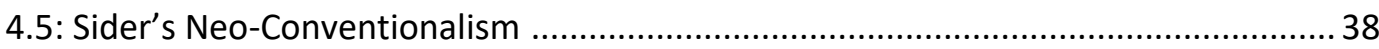




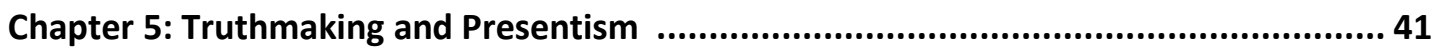

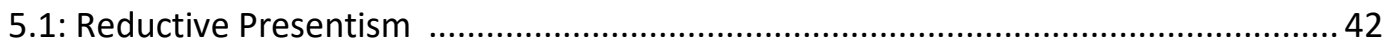

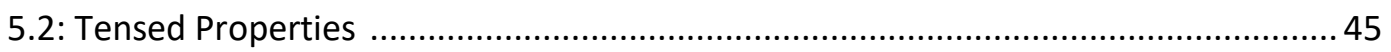

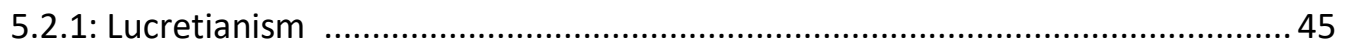

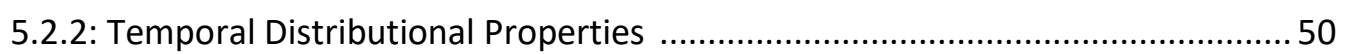

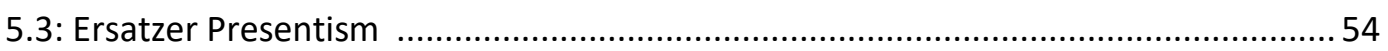

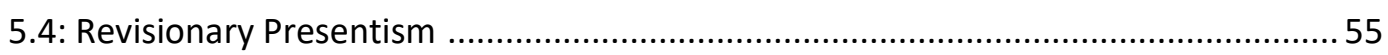

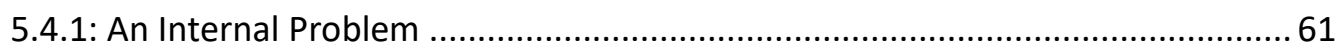

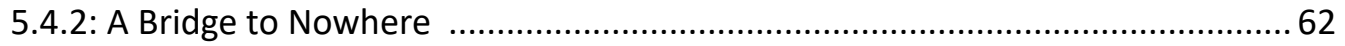

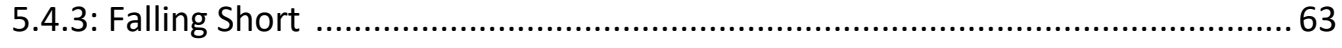

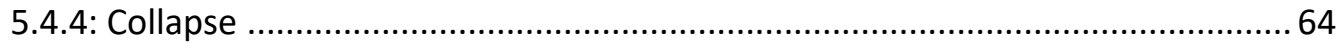

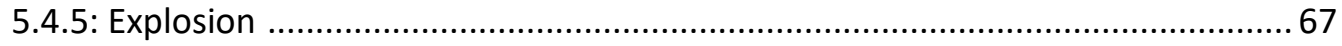

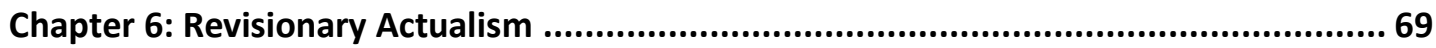

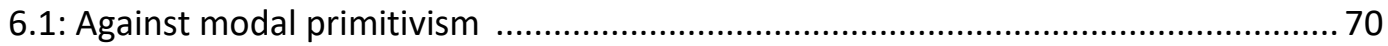

6.1.1: Ostensive Cross-World Causation ............................................................... 70

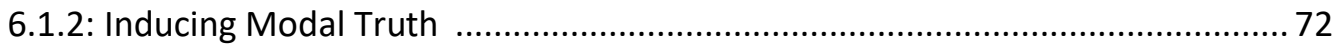

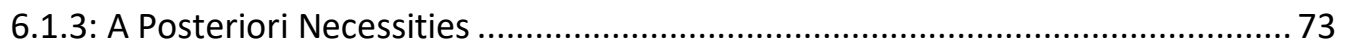

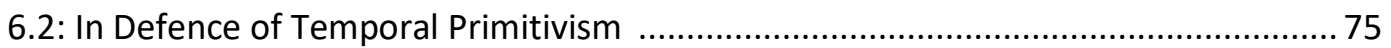

6.3: An Objection from the Modality of Causation........................................................... 76

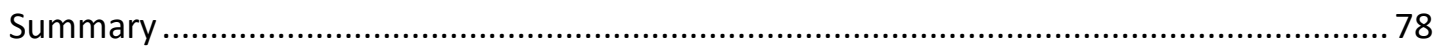

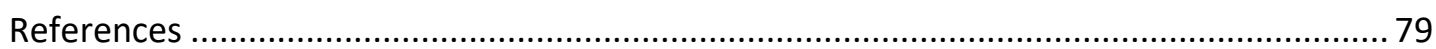




\section{Acknowledgements}

First and foremost I would like to thank my primary supervisor Max Cresswell for all of his advice, encouragement and patience. I would also like to thank my secondary supervisor Ed Mares as well as Simon Keller for helpful discussions at various points during the research and writing processes. Lastly, I would like to thank Sondra Bacharach and the department's postgraduate community for creating such a supportive, stimulating and enjoyable environment to do philosophy. 


\section{$\underline{\text { Introduction }}$}

There is a close structural parallel between the way we talk about time and the way we talk about modality (i.e. matters of possibility, necessity, actuality etc.). A consequence of this is that whenever we construct a metaphysical argument within one of these domains, there is a parallel argument to be made in the other. On the face of it, this parallel between possible worlds and moments in time seems to commit us to holding corresponding attitudes to the ontological status of non-present and non-actual entities.

In this thesis I assess a claim made by Sider (2001: 41-42) that truthmaking - the idea that truth is grounded in existence - provides a way to avoid the commitment to ontological symmetry that this world-time parallel seems to foist upon us. Truthmaking challenges presentists, who deny the existence of past entities and actualists, who deny the existence of merely possible entities, to come up with a way of grounding truths that are ostensively about the events and entities that they deny exist. Sider's claim can be broken down into three propositions:

1. Truthmaking provides reason to reject presentism.

2. Truthmaking does not provide reason to reject actualism.

3. Truthmaking breaks the ontological symmetry between time and modality.

In this thesis I argue that while 1 is false, 3 remains true. While I am not a presentist myself I do not think that truthmaking provides a sound basis for rejecting the position. Much of this thesis is dedicated to defending presentism against the challenge truthmaking poses. I also don't believe that truthmaking undermines actualism, but do not commit myself to any particular actualist response to the truthmaking challenge in this thesis. My central aim is to show that the presentist has a viable response to the truthmaking challenge and that this response does not have a viable parallel in the modal case. So while I think that both presentists and actualists can provide adequate responses to the challenge truthmaking poses, truthmaking still breaks the symmetry because the arguments made in defence of each position are very different. So one might rationally accept one argument but not the other.

This thesis comprises six chapters. The first chapter provides very brief outlines of the two debates in the ontology of time and modality; the debate between presentists and eternalists and the debate between actualists and modal realists. In discussing each debate, I also touch upon the closely related issue of the status of tense and actuality, respectively. 
In chapter two I discuss the world-time parallel in more detail, explaining the structural correspondence between temporal and modal ontological theories and semantics. I illustrate the parallel with reference to McTaggart's (1908) argument for the unreality of time, and Forbes' argument that presence is indexical whereas actuality is not. Finally in this chapter, I note that arguments that employ empirical premises are beyond the scope of the world-time parallel. In such cases, structural correspondence does not translate into equal argumentative force.

In chapter three I discuss truthmaking. I begin by explaining and motivating the truthmaking principle that for every truth there is some part of the world, a truthmaker, that makes it true. However, I go on to reject this principle because it fails to accommodate negative existentials. Next I consider an alternative thesis; that truth merely supervenes on existence. This principle accommodates negative existentials, but has the untenable implication that necessary truths do not require substantive truthmakers. So finally I settle on a principle that I call Boolean supervenience. This principle avoids both of the problems that afflict the other two considered. Finally I go on to explain how truthmaking challenges presentists and actualists, and why Sider believes it breaks the symmetry between time and modality.

In chapter four I briefly discuss a series of four responses the actualist might make to the truthmaking challenge. The first three I consider - linguistic ersatzism, combinatorialism, and modal fictionalism - all implicitly employ modal concepts in their analyses and so ultimately succumb to circularity. The last is Sider's neo-conventionalism, which claims that necessity simply picks out certain categories of truth by convention. I argue that this may potentially provide a plausible response, but requires significant explanation and development first.

Chapter five looks at some responses the presentist might make, and some of the challenges facing them. The first I consider is reductive presentism, which attempts to establish past truths by appeal to deterministic laws of nature and the ordinary content of the present. However this approach falls far short of providing all of the tensed truths we want. The second approach appeals to tensed properties of present entities (e.g. being formerly pale) to ground past truths. There are a number of challenges facing this approach, but central among them is that if such properties are the truthmakers for tensed truths then the presentist is committed to a counterintuitive construal of them as being intrinsic and primitive, rather than relational and complex. I also consider a variation of this approach that appeals to distributional properties. I argue that this variation faces similar difficulties. The 
next approach I consider is ersatz presentism, which constructs imitation or ersatz times out of sets of propositions. These ersatz times can then stand in as truthmakers for truths about the past. The main problem with this approach is that it seems that the way the ersatz times are has nothing to do with what actually happened in the past. They merely correspond with to them by stipulation.

Finally in this chapter, I come to the line of response I believe the presentist should take. I propose that the presentist should reject the demand that the truthmaking challenge makes. She should instead adopt a variation of the truthmaking principle that allows for truthmakers that did or will exist. The justification for this move is based on the adoption of a specific kind of ontological temporal primitivism and a specific understanding of the role truthmaking is supposed to play. In the remainder of the chapter I rebut a series of objections to this revisionary presentism. The last and perhaps most challenging of these is that this revisionary approach is too easily applicable to any truthmaking challenge, and so really amounts to a rejection of truthmaking as trivial. My response to this objection is part and parcel of the final chapter.

In the sixth and final chapter I consider the modal parallel to revisionary presentism: revisionary actualism. I argue that there are reasons for rejecting the modal primitivism that underwrites this revisionary approach that do not apply in the temporal case. Specifically, we are not justified in taking modal features as ontological primitives because we have no empirical epistemic access to the non-actual. Conversely, we do have empirical epistemic access to the past, and so are justified in taking it as ontologically primitive. And so the revisionary response to the truthmaking challenge works for the presentist but not for the actualist, thus breaking the symmetry between time and modality. 


\section{Chapter 1: Two Debates in Ontology and Semantics}

This thesis contrasts two relatively young metaphysical debates that have emerged over the past century or so. One concerns the ontological status of the past and the future. The other concerns the ontological status of the merely possible. In this chapter I briefly outline these two debates.

\section{1: Presentism vs. Eternalism}

For most of western philosophy's history, the premise that the past and future do not exist went largely unchallenged. This seems to be the default position of the folk and is reflected in our natural language: certainly past entities like dinosaurs did exist, but they do not exist anymore. Likewise the future and whatever it may bring will exist but does not yet. This antirealism with regard to past and future entities is commonly called presentism. The presentist's complete list of existing objects (i.e. the things that her most unrestricted quantifiers range over) includes present entities like Queen Elizabeth II, Barack Obama, and The Pyramids of Giza; but no Library of Alexandria or colony on the moon. (Of course for a presentist living in $200 \mathrm{BC}$ such a list would include the Library of Alexandria and the Pyramids but exclude the Queen and Barack Obama, and the list of a presentist living hundred years from now might include a moon colony.)

Presentists often claim that their position captures our pre-theoretic intuitions about the nature of time. However, in the last century many, perhaps the majority of, philosophers came to favour a realist alternative view known as eternalism; the view that the past and future exist in just the same, concrete way as the present. The popularity of this view stems primarily from the development of relativity theory, according to which there is no real distinction between time and space. This suggests that non-present times exist in much the same way as non-present places. It is true here in Wellington that the Eifel Tower exists, even if it is not true that the Eifel Tower exists here in Wellington. Likewise, eternalists claim it is now true that dinosaurs exist, even if dinosaurs do not exist now. More precisely, the proposition dinosaurs exist is true now, but the proposition dinosaurs exist now is false.

Spatial presence is a relative matter. 'Here' for me is 'there' for you. From here in Wellington, Melbourne is to the west, but from Perth it is to the east. For most eternalists, another consequence of viewing time as space-like that temporal presence, and more generally tense, is relative in much the same way. 'Now' for me as I write this is 'then' for you as you read it. Genghis Khan is in our past but in Julius Caesar's future. Just as there is 
no objective fact about where here is, there is no objective fact about when now is; tense is not a feature of the world itself, only of our language. This relativistic view of tense is known as B-theory and is endorsed by the vast majority of eternalists. The contrasting view, Atheory, is that tense is an objective feature of reality, so there are objective facts about what is past present and future. Presentism entails A-theory, so all presentists are necessarily Atheorists.

Presentism and eternalism are not the only two positions one can adopt concerning the ontology of time, but they are certainly the most popular. McTaggart (1908) famously argued that time itself is unreal (more on this argument in section 2.2.1). Also a few philosophers (e.g. Broad 1923, Tooly 1997) defend the view that the present and past exist, but that the future does not; a position called the growing block theory or growing universe theory. Ostensively this view accommodates the intuition many people have that the past is somehow settled in a way that the future is not. Potentially, one could argue that the future is real but the past is not, though as far as I'm aware no one ever has. However, the distinctions these positions bring to the debate make no difference to the arguments I make in this thesis, so for the sake of simplicity, I will ignore these less popular alternatives and focus only on presentism and eternalism.

\section{2: Actualism vs. Modal Realism}

There are various ways propositions can be true or false; modes of truth and falsehood. Both $2+2=4$ and there are five toes on my left foot are true, but they are true in different ways. The first is necessarily true; it could not have been false, but the second proposition could have been false, so it is only contingently true. Likewise, $2+2=5$ is necessarily false but there are four toes on my left foot is only contingently so. Modal propositions make claims concerning not just truth and falsehood, but the way in which propositions are true or false; they are claims about matters of possibility.

The development of possible world semantics by Hintikka (1962) and Kripke (1963) provided an extremely successful means of analysing modal propositions and arguments. Given the ubiquity of modal concepts in language in general and philosophical analysis in particular, it is unsurprising that talk of possible worlds has found application in virtually every branch of philosophy. But it is far from obvious what exactly a possible world is. A possible world represents a complete way the world could have been. But as a conceptual analysis this clearly won't do. What makes a satisfactory analysis of 'possible worlds' 
particularly difficult is that because they are an integral part of the analysis of modal concepts, any analysis that employs modal concepts will be circular.

These difficulties were among the primary motivations behind Lewis's $(1973: 86,1986)$ adoption of modal realism, a view that he himself admits is highly counterintuitive. According to modal realism, possible worlds exist, not just as abstract objects or linguistic constructs, but in just the same way as this world you and I inhabit. Our world is one among a multiverse of worlds, one for each and every way things could have been. Each world is a maximal spatiotemporally interrelated whole, so any two objects are part of the same world iff they are spatiotemporally related. Consequently, worlds and their contents are causally isolated from one and other. For Lewis, actuality is indexical, i.e. what is actually true for us is simply what is true in the world we happen to occupy. But for citizens of another world actual truth is whatever happens to be true in that world. If that world happens to contain unicorns, then it is actually true for them that unicorns exist. There is no absolute, world independent measure of actuality.

In contrast, the vast majority other philosophers want to maintain that the world we occupy is the only one that exists and that actuality is an absolute predicate. This anti-realist stance towards concrete possibilia is commonly called actualism. Actualists differ in how they account for possible worlds. Some endeavour to provide a reductive account, arguing that possible worlds are composed of elements found in the actual world. Others take some modal concept as primitive and analyse possible worlds in terms of it. Still others eschew possible world talk altogether. What all actualists have in common is a rejection of the modal realist's claim that there are other worlds out apart from the actual one. For actualists everything that exists is actual. 


\section{Chapter 2: The World-Time Parallel}

It has often been noted that time is analogous to modality (e.g. Prior 1967, Lewis 1986: 20204, Cresswell: 1990, Markosian 2001). It seems that for every temporal locution there is a corresponding modal locution and vice versa. Consequently, whenever one constructs an argument in one debate, there is a parallel argument to be constructed in the other. If the parallel argument is always of equal force, then one would be committed to holding the corresponding position in the other debate. So the world-time parallel seems to commit actualists to presentism, eternalists to modal realism, defenders of absolute actuality to Atheory, and in each case vice versa.

Aside from Lewis, very few philosophers are comfortable accepting the extravagant ontological commitments of modal realism. Many though are strongly in favour of its corresponding temporal position: eternalism. It is these philosophers who should be most concerned by the implications of the world-time parallel. For if it holds, it forces them into a dilemma of giving up either eternalism of actualism. In this way the world-time parallel works for the most part in favour of presentism and modal realism. But in general for anyone who wants to maintain disanalogous positions in each debate, the world-time parallel poses the challenge of finding some argument that does not have a corresponding argument of equal force.

Broader still, even those who maintain corresponding positions in each debate (and are thus not directly challenged by the parallel) may be concerned on purely hypothetical grounds. It seems an odd conclusion that our claims about ontology should be so determined by the structure of our language. Surely the mere way we talk about things has no bearing on whether or not those things exist. Nevertheless this is what the world-time parallel seems to imply, and if this conclusion seems suspect then it is at least an interesting philosophical exercise to figure out where the relevant disanalogy between time and modality lies.

\section{1: The Parallel in Detail}

The world-time parallel emerges as a consequence of the semantic correspondence between modal and temporal talk. Possible world semantics analyses modal expressions in terms of quantification over possible worlds. The earth could have had two moons is true because there is at least one possible world in which it does. More generally, $\diamond p$ iff there exists some world $w$ such that $p$ is true at $w$. Likewise, temporal semantics analyses temporal expressions 
in terms of quantification over times. Sometimes the moon looks red is true because there is at least one time at which it looks red. More generally: [sometimes] $p$ iff there exists some time $t$ such that $p$ is true at $t$. Of course we usually talk about other times in tensed language that specifically refers to the past present or future: [was] $p$ iff there exists some past time $t$ such that $p$ is true at $t$. And of course [will be] $p$ iff there exists some future time $t$ such that $p$ is true at $t$. Possibly $p$ and sometimes, was and will be that $p$ are analysed in terms of existential quantification, over worlds and times respectively.

This correspondence extends right throughout modal and temporal semantics. The actual corresponds to the present: $p$ is actually true iff $p$ is true at the actual world, $p$ is presently true iff $p$ is true at the present time. Contingency corresponds to change: $p$ is contingent iff $p$ is true at the one world but false at some other world, $p$ changes iff $p$ is true at one time but not at another. Necessity corresponds to stasis: necessarily $p$ iff $p$ is true at every world, always $p$ iff $p$ is true at every time.

Note also that this entails that the relations between the terms are also parallel. For example $\square p$ entails $p$ and $p$ entails $\diamond p$; [always] $p$ entails $p$ and $p$ entails [sometimes] $p$.

One can fix the truth of modal statements across worlds by indexing them to specific worlds. So while the truth of $p$ might vary from world to world, the truth-value of $p$ at $w$ is the same in any possible world. Likewise $p$ might be true at some times but not at others, but $p$ at $t$ will always be either true or false.

So for any modal locution there is a corresponding temporal one, and vice versa. And the structural relations between concepts in one domain mirror to those between the corresponding concepts in the other domain. What follows from this is that whenever we make an argument for or against the reality of worlds or times we can construct a structurally equivalent corresponding argument in the other domain, so any conceptual difficulty or inconsistency in one position will be shown up in its correspondent. It is therefore difficult to find any metaphysical grounds for realism or anti-realism in either domain that does not provide equal reason for adopting the corresponding position in the other domain.

Similarly the debate between A-theorists and B-theorists over the reality of tense is reflected in the debate over the nature of actuality. Eternalists tend to be B-theorists though their position is compatible with A-theory. Presentists are committed to A-theory; obviously the present is privileged if it is the only moment that exists. For the B-theoretical eternalist, temporal presence and by extension tense is subject relative. Concepts like now, past and 
future are much like here, north and south. Whether an object or event is here south or north depends on the speaker's spatial location, and likewise whether an object or event is past present or future depends on the speaker's temporal location. For the A-theorist on the other hand tensed propositions are objective. There is an objective present by which tensed propositions can be determined.

Correspondingly, if one maintains that the actual world is in some way privileged, this provides an objective standard for modal truths. Actualists are obviously committed to objective actuality; if the actual world is all that exists then actuality is as objective as existence is. One could consistently maintain that the actual world is privileged whilst still maintaining that other possible worlds exist. As far as I'm aware no philosopher actually endorses this position, though there is certainly a space here that might be worth exploring. But modal realism seems to fit more naturally with Lewis's view that actuality is world relative, i.e. actuality just means obtaining in the possible world the speaker inhabits. So just as the Eiffel Tower is here is false when uttered here in Wellington, but true for the inhabitants of Paris, in this world unicorns do not actually exist, but for the inhabitants of any possible world in which there are unicorns, they actually do. Many other modal truths are world relative too. For example, in our world the fact that copper conducts electricity is a nomological necessity, but there are worlds governed by different natural laws where this is not the case.

\section{2: Illustrating the Parallel}

To illustrate the parallel I will consider two arguments. The first is McTaggart's (1908) classic argument for the unreality of time. This argument provides an opportunity to demonstrate the way parallel arguments can be constructed in a context that is reasonably technical, but hopefully familiar to most readers. The second is Forbes' (1983) argument for a disanalogy between presence and actuality. He argues that there are reasons for taking actuality as absolute that do not apply equally to tense. In my response to this argument I hope to illustrate how ostensive disanalogies often come down to failure to translate implicitly temporal or modal terms.

\subsection{1: McTaggart's Argument for the Unreality of Time}

McTaggart first notes that there are two ways we can go about ordering events into a temporal series: relative to the present (i.e. as past, present or future) or relative to each 
other (i.e. earlier than or later than). The series of events ordered in the first present relative terms is called the A-Series. The series ordered relative to each other is called the B-series. (Hence the names A-theory and B-theory.) With this distinction in place, McTaggart's argument proceeds as follows:

1. The A-series entails a contradiction.

2. Without the A-series there can be no time.

3. Therefore, time is unreal.

The first premise is known as McTaggart's negative thesis; the second is his positive thesis. His negative thesis is sometimes employed by B-theorists to argue against A-theory (e.g. Mellor 1981). His positive thesis or some variation thereof is sometimes employed by presentists to argue against B-theoretical eternalism (e.g. Crisp 2003). Both theses require justification.

McTaggart argument for his negative thesis can be formulated as:

1. The properties of being past being present and being future are each mutually exclusive.

2. According to the A-series each event possesses all three of these properties.

3. Therefore the A-series entails a contradiction.

Clearly something needs to be said in defence of the second premise. Mctaggart's reasoning here is that an events tensed properties change in such a way that it bears each one at some point in time. ${ }^{1}$ Any event $(e)$ that is past $(\mathrm{Pe})$ was future (PFe) and was present (PNe), any event that is present ( $\mathrm{Ne}$ ) was future (PFe) and will be past ( $\mathrm{FPe}$ ), and any event that is future $(\mathrm{Fe})$ will be present ( $\mathrm{FNe}$ ) and will be past (FPe). So every tensed property is applicable to every event. McTaggart anticipates the obvious reply here: None of the properties above are inconsistent with one and other. The properties of being past present and future are only incompatible when borne simultaneously, so $\mathrm{Ne}$ is not incompatible with $\mathrm{PNe}$ or $\mathrm{FNe}$, only with NPe or NFe. But McTaggart argues that this response does not solve the problem, it merely shifts the debate to a higher order where the same problem re-emerges immediately. $\mathrm{NN} e$ is incompatible with NPe and NFe, and every event bears all three of these properties (and every other second order property) too. In order to overcome this second-order

\footnotetext{
${ }^{1}$ Of course if time has a beginning or an end then there will be events at the start or ends of the temporal series that are never in the future or past respectively. But McTaggart's argument run just as well with two temporal predicates as it does with three.
} 
contradiction the defender of the A-series can appeal to a third-order of tense properties, but of course the same contradiction will arise there too, and so on ad infinitum. At every stage of the regress the defender of the $A$ series is faced with a contradiction. Thus the Aseries, McTaggart concludes, entails a contradiction.

Moving on to McTaggart's positive thesis, he argues that the A-series is necessary for time because without it there is no change and without change there is no time.

1. Time requires change.

2. Change requires an A-series.

3. Therefore, without the A-series there can be no time.

The first premise is not entirely uncontroversial, but I will take it for granted for the purposes of this illustration. It is the second premise that is most in need of justification. McTaggart's reasoning is that it is only the $A$-series facts that change through time. An event is first in the future then becomes present and then drifts into the past. In contrast the B-series facts always remain the same. If event $a$ occurs before event $b$ then it will always be the case that $a$ occurs before $b$, regardless of whether $\mathrm{a}$ and $\mathrm{b}$ are past, present or future. Another way to put this is that without the A-series the universe as a whole is static, and if the whole universe does not change, nor can anything within it do so.

Of course the obvious B-theorist response here is that change simply is variation across time, and that neither the facts nor the universe as a whole need to change in order for change to take place. I think this is correct, but my aim here is not to assess McTaggart's argument. Whatever the merits and flaws of this argument, the point I wish to make is that they are equally present in the corresponding argument for the unreality of modality.

\subsection{2: A Modal Parallel to McTaggart}

McTaggart begins by distinguishing the A-series from the B-series. While possible worlds are not ordered in a linear series in the way times are, we can still distinguish two corresponding ways of organising modal talk about events. We can organise them either relative to the actual world or relative to other locations in modal space, i.e. possible worlds. So the modal parallel of the A-series (let's call it the MA-series) references events in relation to the actual world. Our ordinary modal talk is MA-series talk; $e$ is actual, $e$ is possible, $e$ could have happened but didn't, $e$ is impossible etc. The modal B-series (MB-series) references events in a world relative way. MB-series talk is world-indexed; $e$ is actual in $w, e$ is possible in $w, e$ could have happened in $w$ but did not, $e$ is impossible in $w$ etc. 
So the modal parallel to McTaggart's argument is as follows:

1. The MA-series entails a contradiction.

2. Without the MA-series there can be no modality.

3. Therefore, modality is unreal.

Because worlds are not ordered in a linear series, there is no exact parallel to past and no exact parallel to future. Nevertheless the concept 'mere possibility' corresponds to 'past-orfuture'. To say that $e$ is past-or-future is to say that $e$ occurs at some time that is not present. To say that $e$ is merely possible is to say that $e$ obtains in some possible world, but not in the actual world. With this in mind we can construct an argument for premise 1 that corresponds to McTaggart's argument for his negative thesis. ${ }^{2}$

1. The properties of being actual and merely possible are mutually exclusive.

2. According to the MA-series each event possesses both of these properties.

3. Therefore the MA-series entails a contradiction.

Every event that is merely possible (Me), could have been actual (MAe); every event that is actual $(\mathrm{Ae})$ could have been merely possible $(\mathrm{MMe})$. And the anticipated reply is that these are not inconsistent. Actuality and mere possibility are only incompatible when they are coinstantiated in the same possible world. Ae is not incompatible with MMe only with AMe. But of course this appeal to a second order only recreates the contradiction at a third order. $e$ could have actually been merely possible (MAMe). The defender of the MA-series winds up in exactly the same regress as the defender of the A-series.

Now consider the parallel to McTaggart's argument for his positive thesis:

1. Modality requires contingency.

2. Contingency requires an MA-series.

3. Therefore, without the MA-series there can be no modality.

The MB-series consists of world-indexed facts. These retain their truth value in every possible world. It is true that Caesar crossed the Rubicon in our world $w$ then it is true in every world that Caesar crossed the Rubicon in w, and there is some possible world $w^{*}$ in which Caesar chose not to cross the Rubicon and it is true in this and every other world that Caesar did not cross the Rubicon in $\mathrm{w}^{*}$. So because these world-indexed MB-facts are true or false in every

\footnotetext{
${ }^{2}$ Cresswell (1990) constructs a detailed modal parallel of McTaggart's argument for his negative thesis.
} 
possible world they are necessarily true or false, just as B-facts are always true. In contrast MA-facts can change truth value from world to world. It is true in this world $w$ that Caesar crossed the Rubicon, but Caesar crossed the Rubicon is false in $w^{*}$. So without MA-series every fact is a necessary truth, and there is no contingency. Of course the very same reply can be made here as in the temporal case: contingency is nothing more than variation between worlds. We do not need to say that the facts themselves are contingent only that the states of affairs they describe are.

So those who subscribe to McTaggart's argument for the unreality of time, or as is more likely some part of it, seem to be committed to accepting the same line of argument with regard to modality. Accepting his negative thesis compels one to deny any absolute standard of actuality, accepting his positive thesis compels the denial of modal realism, and accepting his entire argument compels the denial of the reality of modality.

\subsection{3: Forbes' Disanalogy between Actuality and Presence}

Forbes (1983) makes an argument that there are reasons to deny that temporal and spatial presence are absolute properties, and that these reasons do not carry over to the modal case. If it is the case that presence is contextual and its modal correspondent actuality is not, then we would have a reason to reject presentism, but no parallel reason to reject actualism. Forbes argument for the disanalogy begins:

"The significant difference between the modal case on the one hand and the temporal and spatial ones on the other is that we move through time and from place to place, but do not move through the other possible worlds in which we exist. Presentness and localness are properties whose changing application is tied to changes in our relations to the things to which they apply, while with modality there is no comparable phenomenon."

The key flaw in Forbes' argument is the contention that there is no modal concept corresponding to movement through time and space. It is of course true that we do not move through possible worlds as we move through time and space. But the problem is that movement itself is a spatiotemporal concept; to move is to change location and to change is, or at least implies, variation between times (or places, e.g. as a road changes as you drive along it). The appropriate parallel is (or implies) being otherwise at a different possible world, i.e. contingency. It is certainly the case that we could have been otherwise. Of course we are only actually the way we are in the actual world, but then we are only presently the way we are at the present moment.

Forbes continues: 
"And if movement is essential to context-dependence, a semantical implication would seem to be as follows. Suppose a speaker $S$ is rooted to a spot all his life and he and other speakers use 'here' as a descriptive name whose reference is fixed by 'the place where $S$ is located'. Then S's counterfactual 'If I had been located elsewhere, "here" would not have referred to here' is true, although 'here' is not an indexical. It therefore follows that it is not sufficient for the introduction of the apparatus of context-dependence that if things had been different, 'the actual world' would have picked out some world other than the actual one."

In light of the temporal analysis of movement just given, the claim that "movement is essential to context dependence" seems to beg the question against those who would argue that actuality is also relative. It amounts to the claim that temporal presence is indexical but actuality is not because variation between times is essential to context dependence. But why should variation between worlds, i.e. contingency, not also suffice? Without an answer to this question we have little reason to buy Forbes' premise. And if Forbes accepts that contingency also allows for context-dependence then his semantical implication fails to follow and his argument comes apart.

\section{3: Empirical Arguments}

Presentism, actualism, eternalism and modal realism are metaphysical theses. As such the arguments in these debates tend to be based on metaphysical grounds. However empirical theories can also impact on these debates. Perhaps the most challenging obstacle facing presentists is reconciling their view with special relativity. Minkowski space-time is a cohesive four-dimensional fabric; it is not partitioned into distinct temporal and spatial manifolds. Consequently there is no notion of absolute simultaneity. Insofar as simultaneity exists it is observer dependent. Yet if presentists are to adhere to the seemingly self evident claim that existence is absolute, their view requires some notion of an absolute present, which in turn requires a notion of absolute simultaneity. Presentist's face a trilemma: they must reject special relativity, deny that it is inconsistent with an absolute present, or rework their theory somehow to do away with the requirement of absolute simultaneity. None of these options seems plausible.

This is a very brief and superficial outline of the argument from special relativity, and there are a variety of replies to be made one the presentist's part. I will avoid going into the details of this argument and the ensuing debate, in part because I lack the scientific expertise to comfortably assess them, but primarily because they do not bear on the broader epistemic point I wish to make. I only raise the argument to illustrate this broader point. 
Insofar as there is a parallel argument to be made against actualism, it lacks the force of the argument against presentism. We might loosely outline the argument from special relativity as follows:

T1. Presentism requires a notion of absolute temporal presence.

T2. Special relativity implies that there is no notion of absolute temporal presence.

T3. There is a consensus among scientists that special relativity is our best available theory.

T4. Where our metaphysical theories contradict scientific consensus, we should revise or reject our metaphysical theories.

T5. Therefore, we should revise or reject presentism.

Now consider the modal parallel:

M1. Actualism requires a notion of absolute actuality.

M2. Special relativity implies that there is no notion of absolute actuality.

M3. There is a consensus among scientists that special relativity is our best available theory.

M4. Where our metaphysical theories contradict scientific consensus, we should revise or reject our metaphysical theories.

M5. Therefore, we should revise or reject actualism.

Premise 1 is equally plausible in both arguments as it pertains to the internal structure of the metaphysical theories. However, whereas in the temporal argument $\mathrm{T} 2$ at least prima facie plausible, M2 is simply false. Special relativity does not say or imply anything about the status of actuality. However, this is because special relativity is a theory about (space-) time, not about modality. Therefore, $\mathrm{M} 2$ and $\mathrm{M} 3$ are not the appropriate modal correspondents to $\mathrm{T} 2$ and T3. As we just noted in the previous section (2.2), when constructing a modal parallel to a temporal argument, it is essential that we translate all temporal concepts into their modal counterparts, even where they are implicit. So special relativity needs to be replaced with corresponding modal theory wherein all of the temporal concepts are replaced with their modal correspondents. It would be far too large a digression to give a complete statement of the modal parallel to special relativity, but just as special relativity theory implies that there is no absolute temporal presence, such a "modal relativity" theory would imply that there is no absolute actuality, perhaps because modality and space are somehow aspects of a single manifold. 
M2*. Modal relativity implies that there is no notion of absolute actuality.

M3*. There is a consensus among scientists that modal relativity is our best available theory.

M2* looks far more plausible than M2. But of course if we are to avoid equivocation, we must also make room for $\mathrm{M2}^{* \prime}$ s awkward sibling M3*. As I hope is obvious, M3* is simply false. There is no scientific consensus around modal relativity; I just made the theory up! Indeed, given the modal nature of the theory it is doubtful that it would even be empirically testable so as to count as a scientific theory at all. (I have more to say about the empirical inassessibility of modal facts in the final chapter of this thesis, section 6.1.) Perhaps a manyworlds interpretation of quantum mechanics might form the basis of a similar, more plausible argument. According to this interpretation, whenever an indeterministic quantum event occurs, all outcomes obtain, each in a different concrete world. Thus for every genuinely possible (as opposed to merely epistemically possible) way things might have happened there is a world in which things actually did go that way; actuality is world relative. But the evidential support for many-worlds quantum theory is weaker than and, more importantly, independent from the evidence for special relativity. The arguments against actualism from modal relativity and from many-worlds quantum theory will not necessarily be of equal force to the argument against presentism from special relativity.

So the broader point is this: where the premises of an argument rely on empirical evidence, the correspondence in the internal structure of temporal and modal talk will not translate into equal argumentative force. Thus empirical evidence might provide independent grounds for accepting an argument without an equal commitment to accepting its parallel. At best then the world-time parallel shows that there are no independent metaphysical grounds for accepting realism in one debate and anti-realism in the other. But if it holds, this is still a very interesting result. It implies that insofar as one is justified in noncorresponding positions, this justification is completely dependent upon the outcomes of scientific progress.

I suspect many metaphysicians with an interest in the semantics and ontology of time and modality would be uncomfortable with this complete reliance on science for the justification of their views. Of course no sound-minded contemporary philosopher would (or at least should) deny that relevant scientific findings should play a crucial role in shaping our metaphysics, but most would maintain that there are also important, independent metaphysical considerations to be taken into account as well. The remainder of this thesis 
focuses on one particular means by which the ontological symmetry between time and modality might be broken on metaphysical grounds. 


\section{Chapter 3: Truthmaking}

Sider (2001: 41-42) argues that considerations of truthmaking can provide reason to reject presentism that does not carry over as reason to reject actualism. In this chapter I discuss truthmaking and more generally the idea of grounding truth in ontology. I first explain and motivate grounding in terms of the truthmaking principle that every truth has a truthmaker. But in light of this principle's inability to accommodate negative existential truths, I consider an alternative, supervenience based version of the truthmaking principle. But this principle is also flawed: it implies that necessary truths do not require substantive truthmakers. I argue that this implication is implausible, and so instead endorse a third alternative based on Boolean supervenience. Finally I explain the challenge truth grounding poses for presentists and actualists, and Sider's reasons for thinking that the latter camp can meet this challenge whereas the former cannot.

\section{1: The Truthmaking Principle}

Realists about truth believe that truth is grounded in reality. The truthmaking principle purports to capture this intuition. According to the truthmaking principle, every true belief, sentence, proposition (or whatever the appropriate bearer of a truth value is) is true in virtue of some concrete constituent of reality, like a fact ${ }^{3}$ or state of affairs. This part of reality is the truthmaker for the truth bearing entity. I wish to remain neutral on the question of what the appropriate primary bearers of truth are. I will use the neutral term truth-bearer where possible. Where this is awkward or cumbersome (such as in talking about specific examples) I will talk about propositions. But none of the arguments made in this thesis depend on truthbearers being propositions in particular. So you may substitute your preferred truth-bearers for propositions as you so wish.

So a truthmaker is a part of reality that makes its truth-bearer true. More needs to be said about precisely what is meant here by "making true" (and by "in virtue of" in the previous paragraph). A truthmaker's existence is supposed to be sufficient for the truth of the truthbearer. However this relation is certainly not a causal relation. Causal relations hold between physical events, and a truth-bearer's semantic value is not a physical event. The truth of the proposition I am typing is not an effect of my typing; it is more immediate than that. Nor is

\footnotetext{
${ }^{3}$ I use the term 'fact' it a non-linguistic sense after Russell. Roughly, a fact is a complex composition of individuals exhibiting qualities or standing in relations.
} 
truthmaking a relation of logical entailment. Logical entailment holds between the truthbearers, yet whatever a truthmaker may be, it cannot simply another truth. If all that grounds the truth of one truth-bearer is that of another, there remains a question of what makes this other truth-bearer true. If this regress does not eventually appeal to something other than the truth of a truth-bearer, it will either be infinite or circular. Neither of these possibilities constitutes grounding. So truthmaking is neither a purely physical entailment, like causation, nor a purely semantic one, like logical implication. Instead it provides a cross-categorical link between the two domains. Truthmaking is a sui generis non-logical entailment that holds between the constituents of the world (e.g. entities existing, events occurring, relations holding and properties being instantiated) and the semantic value of truth-bearers.

While truthmakers are always sufficient for the truths they ground, they are not always necessary. For example, my existence makes true there are humans but the truth of there are humans does not necessitate my existence; the existence of any other human would also make this true. So many truthmakers can each be individually sufficient for a single truth. Also any single truthmaker will ground many (likely infinitely many) truths. Thus the relationship between truthmakers and truth-bearers is not one to one but many to many.

\subsection{1: Truthmaking Applied}

Many realists about truth find some version of the truthmaker principle prima facie plausible or even bordering on self-evident (e.g. Armstrong, Bigelow, Lewis, Sider, Russell, to name a few). However, some truth realists reject truthmaking for one reason or another. I do not intend to make converts of these sceptics in this thesis. In this section I will say a little to motivate the idea of truthmaking and present some applications of the principle. The arguments I make in this thesis concern only the compatibility of grounding with presentism and actualism, not the plausibility of these theories directly. ${ }^{4}$ But even if one does not buy the truthmaking principle (or the supervenience variation of it I present later in the chapter), the underlying disanalogy that truthmaking shows up may potentially be leveraged in other ways.

Given the apparently self-evident nature of the truthmaker principle one might suspect that it is merely an innocuous truism; if one sees truthmakers as cheap and plentiful then

\footnotetext{
${ }^{4}$ I think the challenges truthmaker theory poses can often be reposed in terms of other principles. My dominant concern in this paper is with the tension between truthmaking and presentism and I suspect that even if one rejects truthmaking the arguments made in this paper may have particular relevance to the problem of accounting for cross-temporal relations.
} 
one might trivially accept truthmaking but deny that it is of any metaphysical importance. In particular if one accepts that any fact can constitute a truthmaker then every true proposition will have a corresponding fact that will trivially make it true. Facts may well provide plausible truthmakers, but in order for the principle to retain its bite, we must limit the class of eligible facts somehow. Ideally we should hope to restrict the truthmaking base to facts concerning the subject matter of physics: bodies, forces and the spatiotemporal relations they bear to one and other. Defining this set satisfactorily is not an easy task and not one I will attempt to accomplish here. But assuming such a set can be defined, with its base narrowed in this way the truthmaker principle poses a challenge to a significant array of metaphysical theses. Indeed Merrick argues at length in Truth and Ontology (2007) that the principle's inconsistency with several plausible semantic primitives and metaphysical theses (namely: negative existentials, presentism, actualism and subjunctive counterfactuals of freedom) outweighs whatever prima facie appeal it may have.

Between these two extremes, defenders of the truthmaker principle argue that it provides a useful litmus test for metaphysical claims. It tethers our semantics to our ontology, enabling us to rule out ontologically dubious positions by ensuring that our semantics doesn't write cheques that our ontology cannot cash. Truthmaking does not rule out any particular ontological claim, or any particular semantic claim. But it does make sure the two are coherent. If I want to claim that it is true that 'unicorns exist' this is perfectly consistent with accepting the truthmaker principle, but my ontology had better be erroneous in the same way, i.e. I had better include unicorns in my ontology.

Armstrong (2004: 1-3) provides two examples of how truthmaking can bring to light such discrepancies between ontology and semantics. Firstly, truthmaker theory provides a basis for refuting phenomenalism, the doctrine that physical objects are reducible to sense data. Perhaps the most difficult obstacle facing this view is accounting for physical objects when no one perceives them. The standard solution to this problem is to appeal to counterfactuals; physical objects consist in the sense-data that would exist if they were perceived. The problem truthmaker theory poses is that these counterfactuals do not seem to have any truthmakers; they do not depend in any way on what exists according to the phenomenalist, but entirely upon what would exist. The second target in Armstrong's sights is Ryle's (1949) philosophy of mind. Ryle accounts for beliefs and certain other mental states in dispositional terms. A belief is a disposition to behave in certain ways in certain circumstances. A belief, like any disposition, may never manifest itself. But if it does not, what makes it true? Today 
I think most would be inclined to say that a disposition is grounded in the intrinsic properties of thing disposed. In the case of beliefs and other dispositional attitudes, this would mean grounding in facts about the neural states of the believer. However Ryle was working in a climate of behaviourism and was thus reluctant to peer inside the black box between our ears or address metaphysical concerns like grounding truth in ontology. But if we accept the truthmaker principle we are challenged to say more. Unless we are willing to take dispositional properties as primitive, we must somehow ground them in the intrinsic physical nature of their bearers.

If one thinks that dispositions can be analysed in counterfactual terms and that counterfactuals can be analysed in modal terms, then these problems reduce to a general problem of grounding modal truths. But unless one is willing to reify possible worlds, this is a difficult task. For the modal realist finding truthmakers is simple. If modal propositions are simply quantifications over existent possible worlds then they are made true by the worlds themselves and their contents. If however, we want to avoid the extravagant ontological commitment of concrete possible worlds, then we need to find truthmakers among the contents of the actual world. And of course there is a parallel problem for presentism. Whereas eternalists can ground tensed truth in existing past and future entities, the presentist must make do with only the contents of the present. I will have much more to say on these challenges momentarily. But first, there is a problem with the truthmaker theory as stated so far that needs to be addressed.

\subsection{2: Maximalism and Negative Existentials}

The formulation of the truthmaker principle currently under consideration stipulates that every truth has a truthmaker. This doctrine is called maximalism and is to my mind untenable. The problem is that there seems to be no truthmakers for negative existentials (and universal generalisations which are logically equivalent). If the truthmaking principle rules out such obvious and indispensable truths, then it is hardly a problem for any other proposition to be in the same boat.

Supposing for example that it is true that there are no sober Irishmen (or equivalently that all Irishmen are drunk), what part of reality makes it true? Perhaps the obvious answer is simply the sum total of all the Irishmen. After all this group seems to be what the expression is really talking about. But the set that comprises the sum total of the existing Irishmen (all of whom happen to be drunk) could potentially exist alongside a sober one, in which case 
the proposition would be false. The existence of the truthmaker is supposed to be sufficient for the truth of the proposition, but the mere existence of this group of particular drunken Irishmen is not enough to make it true that there are no sober ones. More generally, the existence of any set will not be sufficient for the truth of a negative existential because there could always be some additional entity outside that set to falsify it.

To overcome this problem, some appeal to facts in addition to particulars. Russell's opinion of negative facts and the like varied throughout his career but in his Logical Atomism lectures (1972) he posited negative, existential and general facts in addition to atomic facts. Armstrong, a staunch defender of maximalism, continues in this spirit but believes that Russell overdid things by positing so many additional facts. He argues that all that is required in addition to particulars is a single totality fact. The content of the world in conjunction with the totality fact that the world is all there is is enough to entail the truth of negative existentials.

There is something suspiciously ad hoc about appealing to negative/totality facts to account for negative existentials/generalisations. They seem specifically tailored to address the problem they solve. If we can employ tailored facts to solve this problem why not do the same in every other case that truthmaking becomes problematic? There is no obvious principle that would allow these but rule out employing brute dispositional, counterfactual, modal or temporal facts. But as I argued above (section 3.1.1) if truthmakers are this cheap, then truthmaking becomes trivial. For the truthmaker theory to have any bite, truth must ultimately be grounded in a principled set of basic facts that are independently distinguished; ideally a set of fact about concrete particulars instantiating physical properties and bearing physical relations to one and other.

\section{2: The Supervenience Thesis}

More generally, it seems simply silly to go looking for something in the world to ground negative existentials. They are not made true by what exists but by what does not. We should instead reject maximalism; it is leading us on a wild goose chase. Bigelow (1988: 130-133) proposes the thesis that truth merely supervenes on being. Rather than saying that every truth is made true by some part of the world, we should instead say that what is true supervenes upon the entities that exist and the properties and relations they instantiate; if our ontology were different then the truth would be different. Given this weakened principle 
we can say that what makes negative existentials true is that something which does not exist would do so if they were false. So in effect, negative existentials are not made true by any particular obtaining state of affairs, but are true because nothing exists to falsify them. This is in line with the nature of negative existentials; to deny an existential proposition $p$ is to assert that $p$ lacks a truthmaker. So a truthmaker for $p$ is a falsemaker for $\sim p$.

Armstrong (2004: 55) considers and rejects this falsemakers approach. He notes that all true expressions lack falsemakers, yet this does not exempt other truths from the requirement for truthmakers. But In the case of positive existentials, it is not just that there happen not to be falsemakers for them; rather it seems impossible to even imagine how any particular state of affairs could make them false. Falsemakers are irrelevant to what makes positive existentials true. The case is the exact inverse of negative existentials: there are and could be no falsemakers for positive existentials, but they can have truthmakers. So it is the absence or presence of truthmakers that determines the truth-value of positive existentials. In contrast negative existentials can only have falsemakers so their truth-value is determined by their presence or absence.

\subsection{1: Grounding Necessary Truths}

The supervenience thesis offers a plausible solution to the problem of negative existentials. However I think it should be rejected because it carries the implausible implication that necessary truths do not require substantive truthmakers. Depending on how we characterises supervenience, the thesis either implies that necessary truths are made true by anything or makes an unintelligible demand. Suppose we phrase the supervenience thesis as "if the truth were different then the ontology would differ". Then I think the demand that necessary truths supervene on being is unintelligible, as the antecedent is impossible. ${ }^{5}$ If instead we understand supervenience in material conditional terms, i.e. "no change in truth without change in ontology", then anything will serve as a satisfactory truthmaker for every necessary truth. So because necessary truths could not have been otherwise, the supervenience thesis entails that they require no substantive truthmakers.

\footnotetext{
${ }^{5}$ It is worth noting that certain counterpossibles do seem at least prima facie intelligible. Ed Mares (2004: 147) offers the example "if Sally were to square the circle we would be surprised." I do not wish to come down on either side of the debate as to whether or not there are intelligible counterfactuals in this thesis. I only wish to claim that there are some unintelligible counterfactuals and as such some demands for truthmakers for necessary truths that are unintelligible. Furthermore, even if I am wrong in this claim, it only goes to support the point that necessary truths do in fact require truthmakers, which is precisely the conclusion I hope to establish in this section.
} 
This implication is reason to reject the supervenience thesis, but not without independent argument for the claim that necessary truths require substantive truthmakers. I think that we have prima facie reasons for seeking truthmakers for necessary truths. Intuitively the question of what makes a particular necessary truth true is intelligible and some candidate answers are far more plausible than others. For example, the necessary truth it is raining or it is not might be made true by the fact that it is raining outside, or alternatively by the fact that the proposition's disjuncts exhaust all possibilities. Both of these candidates have a degree of plausibility and there is a genuine debate to be had here between them. The fact that there is a frog croaking somewhere in the Amazon however, seems utterly irrelevant. While it is raining or it is not may be a logical implication of this fact, it seems wrong to claim that it is made true in virtue of it.

Nevertheless, several philosophers do deny the need for substantive truthmakers. As noted above, necessary truths do not depend on the world being any certain way. One might deny that they require truthmakers at all because they are in a certain sense self-sufficient; that their own internal nature is enough to make them true. Mellor (2003: 213) seems to believe something along these lines, writing that "because the identity of a necessary proposition entails its truth, [he] cannot see why any other entity must exist to make it so." One might object here that not all necessary truths are obviously self-sufficient in this way; in particular I have in mind Kripkean synthetic necessities like water is $\mathrm{H}_{2} \mathrm{O}$. There is nothing in the internal structure of such propositions that necessitates their truth. But even in the case of analytic necessities, I think there is still an intelligible demand for truthmakers to be made. First of all, it is important to pry apart the metaphysical question from the epistemic one. It is certainly the case that we can justify analytic truths a priori by examination of their internal structure. But this epistemic fact does not necessarily entail that it is this internal structure that makes the propositions true. Claims like it is raining or it is not seem to be about the weather, not their own internal structure. And while intensionality, like justification, is an imperfect proxy for truthmaking, such considerations should provide some counterweight to the claim that analytic propositions are made true by their own internal structure.

And even if it is the case that necessary truths are self sufficient, this may show that they need no external truthmakers, but it doesn't mean they have no truthmakers at all. I see no reason why facts about the internal structure of a proposition cannot constitute a substantive truthmaker. One might be concerned that this relation between the 
proposition's truth value and the proposition's own structure is not the kind of crosscategorical relation truthmaking is supposed to be. But the categorical divide in question is between the content of our ontology and the semantic value of our truth-bearers. Provided the truth-bearers themselves are included in our ontology, there is no reason why they cannot act as truthmakers as well as truth bearers.

Another argument to be considered is that every single entity is a truthmaker for necessary truths because necessary truths are entailed by every proposition. So for any given entity $x, x$ is a truthmaker for the proposition $x$ exists, and for any necessary proposition $p, x$ exists entails $p$. Thus for any entity $x$ and any necessary proposition $p, x$ is a truthmaker for p. This argument rests on two assumptions. The first is that truthmaking is closed under logical entailment: if $x$ is a truthmaker for $p$ and $p$ entails $q$ then $x$ is a truth maker for $q$ also. Call this assumption the entailment thesis. The second is that necessary truths are entailed by any proposition. This is called the spread law $w^{6}$ and is a corollary of strict implication. Both of these claims have a degree of intuitive plausibility. But Restall (1996) notes another plausible principle which seems to show by reductio that at least one of them must be false. The principle he calls the disjunction thesis, states that if a truthmaker makes a disjunction true it must make at least one of its disjuncts true. But for any contingent truth $p,(p \vee \sim p)$ is necessarily true. If the entailment thesis and spread law hold then any truthmaker $x$ makes $(p \vee \sim p)$ true. But by the disjunction thesis, if $x$ makes $(p \vee \sim p)$ true it must also make either $p$ true or $\sim p$ true. Given that we have assumed that $p$ is true, $\sim p$ must be false. So for any truthmaker $\mathrm{x}$ and any contingent proposition $\mathrm{p}, \mathrm{x}$ makes $\mathrm{p}$ true.

This suggests that something more is required for truthmaking. Truthmaking is often characterised as the relationship a proposition bears to the part of reality in virtue of which it is true. This suggests that a truthmaker should not merely entail the truth of a proposition but should somehow be relevant to the appropriate explanation of its truth. The spread law is one of the so called paradoxes of implication that motivates relevance logic. So one option here might be to reject strict implication in favour of some variety of relevance logic. Alternatively though, we might add a relevance criterion to truthmaking rather than logical implication. If we could make either option work then we would have a clear mandate for the demand for substantial truthmakers for necessary truths. But I think we have more cause for optimism if we opt for the latter option. One of the obstacles to developing a satisfactory

\footnotetext{
${ }^{6}$ This use of the term spread law follows Read (2001). The term is used elsewhere (e.g. Brady 2004) to refer to the inference $(p \& \neg p) \vDash q$.
} 
relevance logic is that relevance seems to be about content whereas logic is supposed to only concern form. But there is no such restriction on truthmaking; we can happily add a clause to the effect that a truth bearer's truthmaker must be somehow topically relevant.

These musings on the employment of a relevance clause are somewhat speculative. However I need not commit myself to this or any other particular explanation of what addition is required for truthmaking. The important point I have established is that there are reasons to doubt the above argument that anything can be a truthmaker for a necessary truth. I have also rebutted the claim that necessary truths require no truthmakers at all. With these two concerns quelled, I think that prima facie considerations tip the balance in favour of the claim that necessary truths do require substantive truthmakers.

\section{3: Boolean Supervenience}

So I believe that supervenience is necessary but not sufficient for truth, because mere supervenience absolves necessary truths of the need for substantive truthmakers, and that truthmakers are sufficient but not necessary for truth because negative existentials no not require them. So the maximalist truthmaker principle is too demanding but the supervenience thesis is too lenient. What we require then is something in between that allows that negative existentials only supervene on being but demands more of necessary truths. To this end, I think we need to account for the mechanism by which negative existentials supervene on being.

I noted above (section 3.2 ) that negative existentials can have falsemakers but not truthmakers, whereas inversely, positive existentials can have truthmakers but not falsemakers. This inversive relationship obtains because negation is a truth-functional connective that inverts the truth value of its operand (assuming bivalence). Truthfunctionality explains the mechanism by which negative existentials supervene on being. As Parsons (2005) notes, negative existentials are negations of propositions that would have a truthmaker if they were true. But we cannot simply say that in general every truth either has a truthmaker or its negation would have a truthmaker if it were true. There are complex propositions, like either there are no cubes or there is a sphere, that can be true without a truthmaker (in the case there are no cubes) and yet their negation would also lack a truthmaker if true (as nothing can make it true that there are no spheres). The most we can say, according to Parsons, is this: 
(BST) Every truth either has a truthmaker, or is some complex Boolean function of propositions that are either have truthmakers or would have a truthmakers if true.

Call this the Boolean supervenience thesis. There is a set of basic truth-bearers which are made true by facts, states of affairs, or whatever truthmakers are ordinarily supposed to be. Truth-functional connectives allow us to construct complex propositions that derive their truth-values by logical entailment from the basic truth-bearers that constitute their operands. In a way, his view can be understood as a kind of maximalism that allows complex truthfunctional propositions to be made true by the truth-values of their constituents, except that the relation between complex and basic propositions cannot be properly considered truthmaking as it is not cross-categorical relation between ontology and semantics, but rather a purely semantic implication. Nevertheless, complex propositions supervene on the existence of truthmakers that their basic constituents have or would have were they true.

This Boolean supervenience thesis provides a plausible solution to the problem of negative existentials, whilst still requiring truthmakers for necessary truths and retaining the intuitive appeal of the original principle. It also retains a prima facie potential to undermine a significant variety of metaphysical theories. So it is this thesis that I will employ for the purposes of this thesis, and that (unless otherwise stated) I have in mind when discussing truthmaking and grounding.

\section{4: Truthmaking and the World-Time Parallel}

Truthmaking poses parallel challenges to anti-realists in both the temporal and modal debates. The presentist is challenged to find truthmakers to ground temporal truths without reifying other times, and for actualists the challenge is to find truthmakers to ground modal truths without reifying other possible worlds. If one antirealist position can provide a solution to this challenge that does not have a feasible parallel, then the truthmaking principle would provide independent metaphysical grounds for accepting that position but not the other. Sider argues $(2001: 41-42,2003)$ that actualists can provide such a solution. He contends that it is possible to ground modal claims in the actual world but not possible to ground temporal claims in the present.

Sider's argument that presentism is incompatible with the supervenience thesis is one of several arguments he puts forward against presentism in his book Four-Dimensionalism (2001: 35-42). After first explaining the grounding problem, he goes on to argue that the 
presentist cannot ground tensed truths in the content of the present alone. Any attempt to do so either fails to determine all of the tensed truths, or cheats by positing irreducibly tensed properties, relations or operators. In section 5.2.1 of this thesis I will discuss in more detail what Sider means by cheating and why he thinks the presentist must do so to ground all of the tensed facts. The important point for now is that Sider does not think this argument applies to the actualist. The crucial difference is that there is hope for reducing modality to non-modal notions like logical consistency and analyticity, whereas there is no hope of doing the same for tense operators because there are consistent things that never have and never will happen. Elsewhere, Sider (2003) proposes a positive account of how we might reduce modality to non-modal concepts.

In the remainder of this thesis I argue, contra Sider, that presentists can provide a plausible solution to the grounding challenge. While I share Sider's optimism about the prospect of reducing modality to non-modal notions like consistency and analyticity, I think the particular strategy he proposes will require significant development if it is to work. I also agree with him that tense cannot be reduced to consistency, analyticity or any other nontemporal notion, but believe there is an alternative approach available to presentists. Whereas actualists may be able to give a reductive account of possible worlds, presentists are justified in taking tense as a primitive feature of the world itself, and they are therefore justified in revising the truthmaker principle to accommodate this. This revisionary approach does not reconcile presentism with the truthmaker principle as such, but the revised presentist version of the truthmaker principle does retain the essential spirit of the original version and fulfils the same function of tethering semantics to ontology. So I argue that both presentists and actualists can both provide adequate replies to the grounding challenge. Nevertheless, the fact that presentists and actualists require drastically different responses to the truthmaker challenge is symptomatic of an underlying disanalogy between presentism and actualism, and by extension, time and modality. 


\section{Chapter 4: Truthmaking and Actualism}

My main aim in his thesis is to argue that there is a viable strategy for grounding tensed truth available to presentists, which does not have a viable parallel strategy in the modal case. The question of how actualists might go about grounding modal truth is only of tangential importance to this. Nevertheless, it is worth undertaking a short survey here as a point of contrast for the discussion of tensed truth to follow.

In this chapter I very briefly examine some of the more prominent strategies for providing a reductive account of modality, as well as Sider's (2003) own proposal, and outline some of the challenges facing each one. Like Sider I am optimistic about the prospect of providing a reductive account of modality and thereby grounding tensed truth. It is however far from clear exactly how we should accomplish this. I think the particular strategy Sider endorses fares better than others but requires a substantial development.

First though, there are two preliminary questions to be addressed.

\section{1: Do Modal Truths Require Grounding?}

Some philosophers deny that we need truthmakers for modal truths at all because modal truths are necessary truths and necessary truths require no truthmakers. If we have no need for truthmakers for modal truths but do need them for tensed truth then this offers a clear disanalogy between actualism and presentism. I am happy to accept that metaphysical modal truths (as opposed to e.g. epistemic or nomological modality) are necessary truths. Claims about metaphysical contingency and necessity are unrestricted claims about possible worlds, and as such are true in all possible worlds. But as I argued in the previous chapter (section 3.2.1), necessary truths do require substantive truthmakers. So, therefore, do modal truths.

\section{2: Is a Reductive Account of Modality Necessary?}

If we take possibility or necessity as primitive, then it is easy enough to generate all of the other modal concepts we require. Necessity and possibility are two sides of the same coin. If we have an account of possibility we can analyse necessity as $\sim \sim \sim p$, and given an account of necessity we can analyse possibility as $\sim \square \sim$ p. From this basis we can generate any modal operator we desire. So it would seem that some variety of modal primitivism would offer a 
simple means of grounding modal truths for the actualist. Why then should we bother with trying to produce a reductive account at all?

In order to address this question, I want to first distinguish between ontological and semantic modal primitivism. Ontological primitives are the basic building blocks of reality; objects, properties, relations or other features of reality that are not ontologically reducible to any other feature. On the other hand, semantic primitives are concepts that cannot be analysed without circularity. Neither form of primitivism implies the other. A concept can be a semantic primitive without referring to a primitive feature of the world, e.g. phenomenal categories, like redness or particular kinds of pain seem plausible candidates for semantic primitives, but assuming a physicalist ontology of mind, they are ontologically reducible to neural states. And conversely, some complex concepts pick out ontological primitives. Examples here are harder to come by, but gravity may be one. The concept seems analysable as a force between physical bodies, yet it is at least imaginable that it might be an ontological primitive. And we can also construct them. The concept the-smallest-object-in-existence may well refer to an ontological primitive, but by stipulation it is not semantically primitive (it means "the smallest object in existence").

The ontological modal primitivist takes there to be some features of the world that are irreducibly modal in nature, be they facts, properties, or whatever one takes to the appropriate primitive elements of an ontology. Given some primitive modal features the ontological primitivist should have little trouble providing actual truthmakers for modal truths; she can simply point to the modal features of the world that she posits. But I think this position is epistemically implausible, and argue as much at length in chapter six. To briefly précis the argument, we come to know about the features of the world by empirical means; by observation and inference. But we only ever observe things as they actually are, never as they might have been or not been, and so if there were modal features of the world they would be epistemically inaccessible to us, so we cannot justify positing them.

Semantic primitivism as the name suggests is a claim about our conceptual representation of the world rather than the world itself. The semantic primitivist takes some modal concept(s) to be unanalysable in non-modal terms. Utilising primitive modal concepts, the semantic primitivist can give a reductive analysis of possible worlds into actual objects (e.g. a possible combination of elements of the actual world or a consistent set of actual propositions or sentences). Thus we can account for possible worlds without appealing to any naturally modal ontological features. 
However, if modal concepts are taken as semantic primitives, without some reductive or primitivist account of the ontology of modality, then it seems that modality must be mind dependent. Primitive modal concepts do not reduce to non-modal concepts that pick out non-modal features of the world, nor can they directly pick out modal features of the world. If we take modality as semantically primitive without offering an account of its ontology, modal properties and facts would be cognitive or social constructs that we project onto the world, rather than find in it. And the truthmakers for modal truths would be partly constituted by certain facts about our minds.

Personally, I do not find the consequence that modality is mind dependent all together implausible. Perhaps modal thinking is merely a heuristic we use to navigate the world given imperfect information. After all, we would have little need for modal truths if we knew all the actual ones. However, many philosophers seem to want to avoid mind dependence, though often without explicitly saying why. I think perhaps one reason may be that because modality is so ubiquitous in our analyses of other concepts, accepting that it is minddependant entails a whole host of other concepts are too. So perhaps a reductive account of modality is preferable, however developing one is far from easy.

\section{3: Ersatz Modal Realism}

Given the success of possible world semantics, it is unsurprising that the most popular strategy for reducing the modal to the actual is to give a reductive account of possible worlds, i.e. to construct imitation or as Lewis puts it ersatz possible worlds to stand as proxy for the non-existent concrete possible worlds. But what in the actual world can we reduce possible worlds to?

\subsection{1: Linguistic Ersatzism}

One popular answer is linguistic entities like propositions or sentences of natural language. This view, called linguistic ersatzism, was originally proposed by Adams (1974) and Stalnaker (1976). Linguistic ersatzism maintains that possible worlds are not concrete entities but mere descriptions. A world is a set of sentences or propositions that describes a coherent way the world could have been in every detail. So for a set to constitute a possible world it must meet two criteria, it must be maximal and it must be consistent. The maximality criterion stipulates that the set must fully describe every detail of a world. Thus the set must be unambiguous with regard to every matter; for any intelligible proposition $p$ the set must contain either $p$ or $\sim p$. The consistency criterion stipulates that the sets are consistent in that they contain no 
contradictory subset of propositions. Thus linguistic ersatzism avails its adherents of virtually the same truthmakers that are available to the concrete modal realist. Possibly $p$ is made true by the existence of an ersatz possible world that includes the proposition $p$, necessarily $p$ is made true by the inclusion of $p$ in every ersatz possible world.

The consistency criterion is intended to rule out those world stories that describe impossible worlds. Without this limitation every proposition would be counted as possible and none as necessary. However, as Lewis (1973) argues, it is far from obvious how to cash out the notion of consistency satisfactorily. The linguistic ersatzer might simply say that a set is consistent iff it is possible for all of its propositions to be true together. But this definition makes use of the modal notion of possibility, rendering the analysis circular. Alternatively, she might define consistency in proof theoretical terms; a set is consistent if the denial of its conjoined content is not a theorem of a specified deductive system. But this account will not work because whatever deductive system we employ will inevitably count some necessary falsehood as possible. Arithmetical truths are necessarily true. But as Gödel demonstrated, for any consistent deductive system there is some arithmetical truth that is not among its theorems. So the negation of some unprovable arithmetical truth will come out as possible whatever deductive system we use to define consistency. Thus it seems that the linguistic ersatzer cannot provide a non-circular account that generates all and only the correct modal truths.

\subsection{2: Combinatorialism}

Generally speaking, combinatorialism is the doctrine that possible worlds are combinations of the atomic elements of the actual world. Precisely what these elements are may vary. Armstrong (1989), perhaps the most prominent defender of combinatorialism, advocates states of affairs composed of primitive particulars and universals. Alternatively though, they might for example be materially occupied space-time points, or sentences comprising only primitive concepts. The general hope underlying combinatorialism is that whatever the atomic elements are, they will be such that any combination of them will be possible, thus eliminating the need for the kind of consistency criterion that undoes linguistic ersatzism. So each and every combination of elements will comprise a possible world, and once again we can analyse modal statements in terms of quantification over these combinations of elements just as the modal realist does with her concrete worlds. 
One problem with combinatorialism is that it is not clear that it will generate all of the modal truths we want. For one thing, it seems that whatever the particular atomic elements that comprise the world happen to be, it could have been the case that the world were comprised of something else. If for example the universe turns out to be made up of spatially extended material atomic elements, then combinatorialism limits modal space to worlds comprised of such elements. But even if the world is actually like this, it still seems possible that it could have been comprised of smaller elements or even comprised of infinitely divisible, gunky matter; a world made of play-dough rather than Lego. Similarly, Lewis (1986: 91-92) notes that by restricting possibility to combinations found in the actual world, combinatorialism rules out the intuitive possibility that there might have been "alien" primitives, i.e. primitives that do not actually exist but could have. The general concern behind both of these lines of objection is that the structure of the elements themselves, whatever they turn out to be, seems a contingent matter. In response to this concern the combinatorialist may stick to her guns and argue that contrary to our intuitions these aren't genuine possibilities. The fact that they seem possible to us merely shows that they are possible given what we know, i.e. that they are epistemic possibilities. That combinatorialism does violence to our intuitions in this way is a mark against the theory, but it is far from a knock down argument (especially if the alternative is as counterintuitive as concrete modal realism!). As is common with most philosophical problems, providing a theory that does not conflict with at least some of our intuitions is probably too much to hope for. So this may be a bullet the combinatorialist is willing to bite.

A more troubling objection concerns the combinatorialist's attempt to evade the circularity that plagues the linguistic ersatzer. She does away with the need for the problematic consistency criterion by restricting the contents of her ersatz possible worlds to atomic elements that she hopes are mutually compatible. But doing so creates a new problem. For the linguistic ersatzer defining what it means for a proposition to be true according to $a$ world is straight forward: $p$ is true according to $w$ iff $p$ is a member of $w$, i.e. iff $p$ is a member of the set of propositions or sentences that comprise $w$. But no such obvious definition offers itself to the combinatorialist. Where the proposition in question concerns only atomic elements (e.g. space-time points occupied in such and such a way or some primitive state of affairs obtaining) there will be a direct correspondence between the content of $p$ and a fact about some combination(s) of elements. But when the proposition contains complex concepts that do not pick out these atomic elements directly a problem arises. Take for example the proposition a unicorn exists. In order to assess this proposition's 
truth according to a combination of elements, we must analyse it into a claim about the distribution of such elements. A unicorn is a horse with a horn. Simple enough it may seem, but is it still a unicorn if it loses its horn or if it failed to develop one? Is the fact that it once had the potential to grow a horn enough? And then what is a horse? And what is a horn? Conceptual analysis is a notoriously difficult task, but moreover in this case, the analysis must abstain from employing modal language to avoid circularity. It strikes me as wildly optimistic to hope that we might analyse all of our complex concepts down into claims about atomic elements without modal concepts like potentials and dispositions.

\section{4: Modal Fictionalism}

The claim that Sherlock Holmes lives at 221B Baker Street is, at least in a certain sense, true even though neither Holmes nor 221b Baker Street really exist at all. The sense in which it is true is according to a certain fiction, i.e. according to Conan Doyle's stories, Holmes lives on Baker Street. With the supposition of this elliptical clause we can accept the truth of the proposition without committing ourselves to the ontology it employs. Rosen (1990) argues that we can do something similar with possible worlds. Just as we want to make truth-apt claims about Holmes without committing to his existence, when we analyse modality many of us want to make claims about possible worlds without committing to their existence. According to Rosen we should understand possible worlds talk as in accordance with the fiction that there exist a plurality of concrete worlds, as per Lewis's modal realism. So for any modal expression $p$, there is possible world analysis $p^{*}$ which is true according to the plurality of worlds hypothesis. For example, unicorns could exist is true because according to the plurality of worlds hypothesis there exist some world w such that at w a unicorn exists.

But in this case as in the case of combinatorialism, there is a tacit circularity lurking beneath the surface. In Conan Doyle's stories (and presumably every other fiction) there are semantic gaps; propositions for which the fiction does not determine a particular truth value. For example, Doyle's stories do not stipulate nor imply whether or not Holmes can curl his tongue or what size shoe he wears. In the case of literary fiction such gaps are of no obvious material consequence. However, if we are to base our modal semantics on a fiction, such gaps would lead to indeterminate modal propositions. Of course some degree of modal indeterminacy may be acceptable and perhaps even expected. But it does seem that there is at least a settled core of modal truths for which we agree on the truth values and with 
which we would expect a satisfactory analysis of modality to comply. To meet this demand, the modal fictionalist requires a comprehensive description of the multiverse hypothesised, and to avoid circularity she must generate such a description without employing modal language. But describing the content of the realist's possible worlds in purely actual terms is precisely the challenge that plagues the linguistic ersatzer. And there seems to be no reason why the fictionalist should succeed where she has failed.

\section{5: Sider's Neo-Conventionalism}

Sider (2003) wants to reduce necessity, and with it the rest of modality, to non-modal concepts like analyticity and logical consistency. To this end, he proposes that necessity may in a sense be a matter of convention. However he wants to distance himself from the more traditional brand of conventionalism widely held in the first half of the $20^{\text {th }}$ century, particularly among logical positivists and ordinary language philosophers. These conventionalists follow Hume in distinguishing between propositions that concern relations of ideas and those that concern matters of fact. The former are a priori, analytic and necessary, the latter a posteriori, synthetic and contingent. Consequently, necessary truths are analytic truths and owe their truth to linguistic convention. Necessary truths qua analytic truths tell us nothing about the world but only about the conventional meanings of the concepts and logical operators they employ; as Ayers (1936) put it, necessary truths "do not make any assertion about the empirical world, but simply record our determination to use symbols in a certain way."

Conventionalism has since fallen out of favour, largely due to Quine's sustained assault on the idea of logical truth by convention (e.g. 1936) and the analytic-synthetic distinction (1956), and also Kripke's (1972) extensional deconflation of necessity and analyticity. So like most contemporary philosophers, Sider (2003) rejects the idea that a proposition can be made true purely by convention. But while convention cannot make propositions true, according to Sider's proposal, it can still make them necessary. Certain categories of truth are simply designated as necessary by convention. The obvious categories are analytic, logical and mathematical truths, but there must also be others to accommodate synthetic necessities etc. Unlike traditional conventionalism, neo-conventionalism does not claim that necessary truths are made true by convention, and therefore avoids Quine's critique. Cameron (2009) appears sympathetic to Sider's neo-conventionalism. He notes that an 
implication of the view is that necessity is not a natural property of propositions, but a distinction that we project onto the world. But he is at pains to point out that this is not to say that necessity mind dependent. Even if necessity is not a natural property of propositions, it picks out a set of categories that are natural. Cameron says that a particular truth is necessary because it belongs to one of the categories and there is nothing more to be said about it.

I think Sider's proposal has potential but requires more development. I am not adverse to the idea that necessary truths do not all share a distinguishing natural property, but if so I think we are owed an explanation as to why necessity picks out the categories of truth it does. Why do we have the particular convention we do? Cameron writes that we draw the distinction where we do "because of our interests"; we consider certain kinds of propositions important and so accord them a special modal status. But as an explanation this is far too vague to be satisfying. How exactly is it in our interest to make this classification and why are these particular kinds of propositions important to us? Are they all important to us for the same reason or are different reasons for including different categories under the umbrella of necessity?

I think it is worth noting that the claim that necessity is nothing more than a pragmatic social convention is a hypothesis that has empirical implications, albeit ones that are difficult to nail down and test. Of course I do not want to claim that the hypothesis is empirical in the sense that it is directly about the world; obviously it is an analytic claim about our language. But if it is the hypothesis is true then it has implications for what we would expect to see in the world, in particular in human linguistic behaviour. For example, we should expect to see the convention(s) that comprise necessity tracking variations in the interests that determine them. And if we have different reasons for including different natural categories as necessary then the fact that we have a unifying umbrella term would seem to be an idiosyncrasy of our language that we should expect to vary between language communities. If on the other hand there is a single reason justifying the inclusion all of the natural categories we count as necessary, it seems a more accurate analysis would latch on to this common interest. To construct a slightly absurd analogy, if certain natural categories of propositions made our ears bleed when we heard them expressed, we would have an interest in classifying these categories under an umbrella category. But it would seem that the defining factor of this umbrella category is that its propositions make our ears bleed, not that they belong to one of its subordinate natural categories. 
Personally, I doubt the kind of interest we have is subject to much variation; I suspect it is something about our epistemic relation to necessary propositions that makes them important to us, e.g. we lack the capacity to conceive of them being false. I do not have any argument here beyond an appeal to the limits of my imagination: I cannot think of any nonepistemic distinction that could explain why a proposition's necessity might be important to us. But if this is right then the determining factor in whether or not a proposition is necessary must be some kind of relation it bears to our psychology. So the truthmakers for modal claims would be found in part in facts about our psychology and thus, contrary to Cameron's assertion, necessity would be mind-dependent.

So at a general level I am sympathetic to Sider's proposal. I think that necessity and modality in general may well be properties that we project onto the world. But we are owed an explanation of why necessity picks out the categories it does. And I suspect that it may be difficult to provide such an explanation without appealing to epistemic facts, thereby rendering modality mind dependent. 


\section{Chapter 5: Truthmaking and Presentism}

That there are truths about the past is uncontroversial. I know that I had muesli for breakfast this morning. And most of us know that the Berlin Wall fell in 1989, that Caesar crossed the Rubicon and that Socrates taught Plato. For these things to be known, they must be true. Moreover, there are many more truths about the past that we don't know and in all likelihood never will. For all we know Caesar may or may not have had a boiled egg for breakfast the day he crossed the Rubicon. But regardless of our ignorance, there remains a fact of the matter.

That there are truths about the future is more controversial. Aristotle is famously supposed to have maintained that there is no fact of the matter of whether or not there will be a sea battle tomorrow. This position, that the future is somehow open in a way that the past is not, is still defended today. For some it is among the primary motivations for adopting the presentist position. These open future presentists maintain that presentism avoids the commitment to determinate facts about future entities and events that eternalism entails. For according to eternalism the future exists in exactly the same way that the present exists so there must be determinate (though not necessarily causally determined) facts about it. In contrast if the presentist is correct then there are no truthmakers to determine any facts about the future.

However, this rationale seems applicable to the past as well. According to presentism the past does not exist anymore than the future does, and so it would seem the open future presentist is committed to saying there are no determinate facts about the past either. This is an implication that few would be willing to accept. (This undesirable symmetry motivates growing block theory, i.e. the view that the past exists but the future does not. But there are significant challenges facing this position, and perhaps more importantly, for the purposes of this thesis the distinction between it and eternalism is negligible.)

Of course not all presentists are open future presentists. Some would maintain that there are determinate truths about both the past and the future. But this only doubles the extent of the problem; they are still tasked with finding truthmakers for tensed truths whilst maintaining that the ostensive referents of those truths do not exist. It certainly seems that the present alone does not determine all of the truths about other times. The present state of the world is quite consistent with any number of pasts and futures. 
So the challenge facing the presentist can be framed as a trilemma; she must deny one of the following premises which are together inconsistent with the presentist thesis that everything that exists is present:

1. There are determinate facts about everything that has happened.

2. The content of the present does not determine all of the facts about other times.

3. The truthmaking principle. ${ }^{7}$

In this chapter I consider four responses to this problem. The first approach I will consider I call reductive presentism. It attempts to find truthmakers for past and future truths in the concrete contents of the present. This, I think, aims to reject premise 2 , but ultimately amounts to a rejection of 1 . The second and third approaches, called tensed property and ersatzer presentism respectively more clearly reject 2 . As their names suggest, the tensed properties approach does so by appealing to primitive tensed properties instantiated by presently existing entities, and the ersatzer approach by reducing tensed truth to facts about an ersatz B-series. Both of these, I argue, are ad hoc rationalisations that fail to provide plausible explanations for the truth of tensed propositions. The fourth approach rejects 3 , instead proposing the alternative principle that truth is grounded in what did, does or will exist. So while this approach rejects the truthmaking principle, it is not a rejection of truthmaking in general. This revisionary approach is the only one that I think offers the presentist a plausible solution to the truthmaking problem.

\section{1: Reductive Presentism}

We can know about the past by using information about what exists around us now to make inferences about how things must have been for the present to eventuate as it has. And we can make predictions about the future in the same way: by looking at the present and inferring how things will unfold. In many cases we can use our knowledge of natural law to make extremely accurate inferences about other times.

According to reductive presentism, the metaphysical picture parallels the epistemic one. Just as our knowledge of other times is inferred from our knowledge of the present and our knowledge of natural law, the truths about the past and future are determined by the facts

\footnotetext{
${ }^{7}$ I have in mind here the Boolean supervenience thesis I prefer, but as far as the discussion of tensed truth is concerned any of the three grounding principles articulated in chapter three will have the same implications.
} 
that are exclusively about the present and the facts about natural law. We might characterise a proposition or fact that is exclusively about the present as one that is equivalent to a proposition that uses only present tensed language. Because truths about other times obtain only insofar as they are entailed by present states of affairs and the laws of nature, exactly how much we can say is true about the past and future depends on how deterministic the laws of nature actually are. If they are fully deterministic both forward (i.e. past determines future) and backwards (i.e. future determines past), then there will be a determinate truthvalue for every claim about other times. If the laws of nature are indeterministic in either direction then some propositions will be undetermined and thus indeterminate. But just because a tensed proposition is undetermined doesn't mean there is nothing to be said about it. Propositions about other times may be objectively probable insofar as they are evidenced by the present state of the world. So as time passes facts fade in and out of existence as the evidence for them waxes and wanes.

As far as I am aware, no philosopher seriously endorses this view. Though a few toy with the idea (e.g. Le Poidevin 1991, Ludlow 1999, Sider 2001, Bourne 2006), each ultimately rejects it. One possible exception that both Prior (1967: 29) and Sider (2001: 38) reference is Lukasiewicz (1967: 38-39) who was at least open to the possibility of an open past, though he does not explicitly defend the position that past truth is determined by present facts and the laws of nature.

Sider (2001: 37-38) and Bourne (2006: 47-51) object to reductive presentism on the grounds that one cannot provide truthmakers for the laws of nature themselves given only the concrete contents of the present. If the laws of nature like all Fs are G consist in regularities like $\forall x(F x \rightarrow G x)$ then the presentist ontology will give the wrong laws. There are clearly some nomologically contingent regularities that obtain at present, such as that all humans are less than 10 feet tall. The regularities that determine the laws must be eternal. But for the reductive presentist this move results in circularity: the tensed facts are determined by the laws of nature which are themselves partly determined by tensed facts. So for the reductive presentist, the laws must not be simple regularities: if they are present regularities then there are far too many laws; if they are eternal regularities then reductive presentism is circular.

But this regularity account seems implausible even for the eternalist. There is an independent reason for rejecting this account. There are regularities that obtain across time that are nevertheless not laws of nature. And if laws of nature are supposed to sustain 
counterfactuals, then actual regularity alone cannot account for them. Perhaps a more nuanced and plausible regularity based account might be developed, but even then it is not as though the regularity approach is the only one available. The reductive presentist has other options. For example, Armstrong (1983) maintains the laws are relations between universals that exist in addition to the generalities they entail. So a law that all Fs are Gs consists in a nomic relation between the universals F-ness and G-ness. Thus it is possible for a generality to obtain without being the product of a corresponding law. So this theory allows the presentist to distinguish between nomologically necessary and contingent generalities.

Bourne (2006: 50) argues that in claiming that past and future truth depend upon determination by present facts, the reductive presentist commits the offence of confusing determinateness with determinism. These are certainly distinct notions and to infer either that a proposition is indeterminate from the fact that it is undetermined, or that a proposition is determined from the fact that it is determinate is fallacious. Determinateness does not imply determinism. But the reductive presentist does not make this inference. She infers that tensed propositions have determinate truth values from the fact that they are determined. This inference is perfectly legitimate. And her inferences of indeterminateness are not solely based on a lack of determinism, but rather a lack of ontological grounding in general, including a lack of determinism. Again, this inference is also perfectly legitimate. So in effect, given that determinism is the only kind of ontological grounding available to the reductive presentist for past and future tensed truths, it is perfectly reasonable to equate it with determinateness in these cases.

So I think the reductive presentism can withstand these objections. Nevertheless, I think the insurmountable obstacle that the theory faces is glaring: it must overcome our deepseated intuition that while the future may be open, the past definitely is settled. For the thesis to be plausible the laws of nature must be backwards deterministic. Any metaphysical theory that denies that 'dinosaurs existed' is simply true (not just probable) will almost certainly fail to gain widespread acceptance. The potential to satisfy the open future presentist is perhaps reductionism's main selling point. But to do so the laws of nature must be forwards indeterministic. So ideally the reductive presentist is banking on the laws of nature determining the past but leaving the future largely open. But it seems quite likely that this is the exact opposite of how things actually are. A case can certainly be made that the laws of nature are forwards deterministic, indeterministic interpretations of quantum 
mechanics notwithstanding. And at least on the face of it, it seems that one can concoct fully described states of affairs that do not provide enough information to nomologically determine any antecedent states of affairs. Imagine for example a ball sitting at the bottom of a bowl. It is difficult to imagine how one might go about determining how the ball came to be there. How are we to decide whether the ball rolled in from one edge of the bowl or another? We might look for evidence such as a trail through the dust inside the bowl, but such evidence is at best abductive, not deterministic proof of a given antecedent state of affairs. Moreover we can reengineer the case to exclude such evidence; remove the dust and put the bowl and ball in a vacuum etc. Scenarios like this provide reason to think that very little in the past is nomologically determined, committing reductive presentism to the extremely counterintuitive denial of truths about the past.

Most presentists want to maintain all of our standard beliefs about what is true of the past. So instead of denying past truth, they opt for enriching the contents of the present to include some kind of record of the past. There are two main strategies in this vein. The first is to posit tensed properties of present objects and the second is to posit an ersatz B-series consisting of presently existing sets of propositions. I will now consider each of these in turn.

\section{2: Tensed Properties}

In response to the truthmaker challenge, some presentists appeal to properties of present entities. Take for example the property being 50 years of age. The present instantiation this property entails certain tensed facts; most obviously that 50 years ago its bearer was born. The hope driving this approach is that we can find presently instantiated properties to determine all of the facts about other times. Thus the properties in question must determine the history of their bearer and moreover, precisely how long ago any particular state of affairs obtained. If such properties can be found then they can ground tensed truths without reifying other times.

\subsection{1: Lucretianism}

Bigelow (1996) defends a view of this kind based on the ideas of the Stoics and Epicureans of ancient Greece and Rome, and in particular on the writings of Lucretius. These Ancients were presentists, and were concerned with the problem of relations between present and past events and entities. The Stoics admitted into their ontology abstract propositions, and argued that cross-temporal relations were relations between tensed propositions, e.g. there 
is a causal relation between this man was wounded and this man will die. For Lucretius however, the commitment to the existence of propositions was a bridge too far. His ontology was sparse, admitting nothing "that is distinct both from body and from vacuity"; nothing but atoms and the void. Instead of abstract propositions, Lucretius appealed to accidental properties. He states: "whatever has taken place is an accident[al property] of a particular tract of earth or of the space it occupied." So according to Lucretius, instead of relating propositions as the Stoics argued, cross-temporal relations link properties of present objects. Bigelow notes that this ontology offers a ready solution to the problem of truthmakers. The tensed truths can be grounded in the present instantiation of these tensed properties; if the tensed truths were different then different tensed properties would be instantiated. Bigelow makes one fairly minor revision to Lucretius's theory. One problem facing the theory as sketched so far is accounting for truths about objects that no longer exist and thus no longer bear tensed properties. Lucretius dealt with this problem by appealing to properties borne by tracts of earth or areas of space, e.g. there's a tract of earth somewhere in Greece that bears the property being the place where Socrates previously taught Plato. But to simplify things, Bigelow notes that the world in its entirety is an existing object that has properties. Among these, Bigelow claims, are tensed properties like previously containing dinosaurs and being such that Socrates taught Plato.

This Lucretian approach has not met with widespread acceptance. Many find something ontologically unsavoury about the idea of these ghostly properties lingering in the present, floating free of the physical properties of their bearers. But it is not immediately obvious precisely what it is about these properties that makes them unpalatable, or in what sense they are ghostly and free-floating. Sider (2001: 40-41) attempts to give a principled formulation of this objection. He calls the Lucretian approach "cheating" because the tensed properties are irreducibly hypothetical rather than categorical. Categorical properties are those that involve what objects are "actually like", whereas hypothetical properties "point beyond their instances". He maintains our ontology should only invoke properties that are categorical or can be reduced to categorical properties, not irreducibly hypothetical ones. To illustrate this point, he discusses the example of dispositional properties. The truth that a particular wine glass is fragile must be grounded in the non-dispositional properties of the glass itself and the laws of nature (and perhaps also non-dispositional properties of the environment if fragility is contextual). To say simply that the glass has the brute property of 'being disposed to shatter' seems like cheating. According to Sider this ontological move is 
illegitimate because it posits an irreducibly hypothetical property. The dispositional property in question points beyond what the glass is actually like to the way it is disposed to be.

While Sider's hypothetical/categorical distinction points to the heart of the problem with Lucretianism, I think his response is (as he readily admits) problematically vague. And there is another problem too. His demand that categorical properties must involve only what objects are "actually like" may beg the question against the views against which he hopes to employ this distinction. The phrase simply rules out by stipulation properties concerning how things were, will be or could have been. As such, it is unlikely that any advocate of tensed properties (and for that matter presentists in general) would find his distinction compelling.

I think a clearer way to frame the problem with tensed properties is to ask the question: are these posited properties supposed to be relational or intrinsic? ${ }^{8}$ They must be one or the other but both answers are problematic. Intuitively they seem like relational properties, borne in a cross-temporal relation to the past entities and events they describe. But if they are relational then they require something to relate to, and ex hypothesi the obvious candidates do not exist. Perhaps the Lucretian might engage in some metaphysical wizardry and conjure up some kind of ersatz relata. But any plausible candidate for tensed property relata will also be a more appropriate candidate for the truthmaker for tensed truth in question. So if the Lucretian posits ersatz relata, she abandons her position for something more akin to the ersatzer approach we will consider later in this chapter (section 5.3).

If, on the other hand, tensed properties are intrinsic properties then they are certainly strange ones. An intrinsic property is one that never varies between duplicates. Lewis (1986) defines an intrinsic property as: $p$ is intrinsic iff for any $x$ and $y$, if $x$ is a duplicate of $y$ then $x$ has $p$ iff $y$ has $p$. Lewis defines duplicity thusly: $x$ is a duplicate of $y={ }_{d f}$ there is a one to one correspondence between $x^{\prime}$ s parts and y's parts such that, for any perfectly natural relation $R$, for any $x_{0}, x_{1}, \ldots$ that are part of $x, x_{0}, x_{1}, \ldots$ stand in $R$ iff $f\left(x_{0}\right), f\left(x_{1}\right), \ldots$ stand in $R$. Informally, $x$ and $y$ are duplicates iff they share corresponding parts, and their all parts have the same natural properties and stand in the same natural relations to one and other. This analysis may need some tweaking, but its imperfections should not undermine its application in this case. In effect a property is intrinsic if it supervenes on the natural properties of its object. Whether we can classify a tensed property $\mathrm{F}$ as intrinsic according to this definition depends on whether we could have a duplicate that lacked $F$, and this in turn depends on whether or

\footnotetext{
${ }^{8}$ Keller asks this same question in his unpublished paper How to be a Presentist (cited in Armstrong 2004: 146).
} 
not $\mathrm{F}$ is a natural property or reducible to natural properties. Natural relations are perfectly simple properties, the basic building blocks of nature.

If we accept the physicalist doctrine that higher order properties supervene on physical properties, then an intrinsic property should supervene on the internal physical properties of its bearer. Yet it is not at all clear what physical difference it would make to the present state of world if it lacked the tensed property of previously containing dinosaurs. It is certainly true that counterfactually if dinosaurs had never existed the world would now be a very different place, but as a reply this misses the point. It was the existence of the dinosaurs themselves that caused the world to be the way it is, not the fact that the world has the property of previously containing them. This tensed property is a mere symptom, a causal co-effect of the dinosaurs having actually existed.

So given the Lucretian ontological picture of a three-dimensional present bearing tensed properties, it seems perfectly possible to imagine an exact physical duplicate of the world that lacks any of its past-tensed properties. In response, the Lucretian might offer an alternative account of intrinsic properties that does not require invariance between duplicates, though it is difficult to imagine any such account being plausible. It seems to me more likely that she would instead deny the possibility of such a duplication. I can see two ways she could go about this. She might simply deny that it would be possible to duplicate the world with all of its physical properties without reinstantiating all of its tensed properties as well. But this move looks like a reversion to the failed reductive approach we just rejected (section 5.1) precisely because it is unlikely that facts about the present do determine all of the tensed truths we want to claim. What I suspect is more likely is that she would deny physicalism and maintain that there are primitive tensed properties that are not physical and do not supervene on the physical.

Positing sui generis primitive properties in this way may not be entirely indefensible, but it should certainly prompt suspicion that the move is an ad hoc rationalisation. It would be nice to be provided with some independent motivation for accepting that these properties are primitive. For want of such motivation, I find the Lucretian response to the truthmaker problem quite uncompelling. And furthermore, it is not obvious what principled distinction would allow us to posit primitive tensed properties but prevent us from postulating any other kind of primitive property we might need to suit our needs. If there are primitive tensed properties that can ground tensed truths, why can we not posit primitive modal properties to ground modal truths or primitive dispositional properties to ground dispositional truths? 
Here again, as in the case of indiscriminately allowing facts as truthmakers (section 3.1.1), the prospect of explosion looms. Allowing primitive tensed properties threatens to undermine the force of the entire truthmaker programme.

Crisp (2007) agrees that tensed properties like being such that dinosaurs once existed are implausible candidates for primitive properties. However he argues that such properties are reducible to properties like being such that dinosaurs exist and being past. And it is not so obvious that the latter is not a primitive property, at least not for presentists. But even if such tensed properties are primitive, clearly being past is not a property that can be borne by any concrete object in the presentist's ontology. Instead, Crisp claims that properties like being past are borne by propositions. But if this is the case, then I think we are owed an account of how they are supposed to ground tensed truths. The propositions that bear these properties are the truth-bearers in question. I do not wish to claim that a proposition's properties cannot make their bearer true in any circumstances. Indeed, in section 3.2.1 I argued they might do so in the case of analytic truths. But in this case it seems implausible. Propositions do not simply make themselves true by virtue of bearing tensed properties; there are as many false propositions bearing tensed properties as there are true ones. So there must be some factor beyond the tensed properties of the proposition that at least contributes to making the proposition true.

So, while we should not deny that objects have these tensed properties, we should say that they are not intrinsic (nor primitive), but relational. This is very much in line with the concern that Sanson and Caplan (2010) have with Lucretianism: taking tensed properties as primitive intrinsic properties suggests the wrong kind of explanation for tensed truth. Take the proposition Arnold was pale. According the Lucretian, this proposition is true because Arnold presently instantiates the property having been pale. But there is an alternative explanation available; Arnold was pale is true because Arnold previously instantiated the property being pale. Sanson and Caplan argue that this is the more appropriate explanation. It is certainly true that both facts entail that Arnold was pale, they are after all logically equivalent. But mere entailment is not enough for explanation or truthmaking. It seems appropriate to say that Arnold presently instantiates the property having been pale in virtue of previously instantiating the property being pale, but not the other way around. It is the previous instantiation of the present-tensed property that is at the heart of the explanation. The presently instantiated past-tensed property is merely a symptom; a relation borne to a past Arnold that is pale intrinsically. 
Of course it is not obvious how the presentist can endorse an explanation that employs facts about properties being instantiated in a past that she denies exists. But the revisionary approach that Sanson and Caplan propose and that I argue for at the end of this chapter (section 5.4) allows her to do just this. Now though, I turn to consider a variation of the tensed properties approach based on Parsons' (2004) idea of irreducibly distributional properties.

\subsection{2: Temporal Distributional Properties}

Cameron $(2008,2011)$ agrees with Sider and others that there is something suspicious about Lucretian's properties and so proposes a revision of the tensed properties approach. According to Cameron, their problem is that they make no difference to the present ${ }^{9}$ intrinsic $^{\circ}$ nature of their bearers. Properties that fail to make such a difference should be rejected from our ontology. Thus to reconcile her view with the truthmaker principle, what the tensed property presentist needs is to find properties that both make a difference to the intrinsic nature of their bearer and fix truths about the bearer's past. To this end Cameron proposes an appeal to distributional properties.

The significance of distributional properties was originally proposed by Parsons (2004), who offers examples like a surface being polka-dotted, a poker being hot at one end and cold at the other and an object having a uniform density of $1 \mathrm{~kg} / \mathrm{m}^{3}$ throughout. Parson's explicitly avoids providing a definition of the term to avoid question begging in his arguments, but we might loosely characterise distributional properties as the distribution of a feature across some dimension(s). Parsons argues that distributional properties are not reducible to nondistributional properties, or more specifically that they are not necessarily co-extensional with any non-distributional properties. Parson's argument here is essentially that we cannot rule out the possibility that properties are distributional all the way down, and if this is possible then we cannot say that distributional properties are necessarily co-extensive with any non-distributional properties. Take for example the property of being polka-dotted. The obvious reduction here would be to say that the fact that a surface is (say) white with red polka dots is reducible to its being white in some places and red in others, i.e. it is equivalent to a massive conjunction of non-distributional properties like being red here and being white there etc. But, Parson argues, the parts that are red are so in a distributional way. Suppose that the redness of the dots is slightly variable in pitch or tone. Then we can say that the red

\footnotetext{
${ }^{9}$ As Cameron notes, for the presentist this 'present' is redundant. An objects intrinsic nature is exhausted by its present intrinsic nature.
} 
is distributed unevenly. And if the dots are exactly the same red all over then the redness is distrusted evenly. Unless there are some unextended points to which we can ascribe nondistributional properties it seems that the properties that compose redness will be distributional all the way down. That the world is composed of unextended points like this is certainly not uncontentious, and even if it is the case it seems it could have been otherwise. Thus distributional properties are not necessarily co-extensive with non-distributional properties, and therefore not reducible to them.

Cameron argues that the presentist can employ temporal distributional properties to ground tensed truths because, like the tensed properties of the Lucretian, distributional properties determine something about the past, but unlike the Lucretian's properties, they also determine something about the present intrinsic nature of their bearers and are therefore eligible for inclusion in our ontology. So to take Cameron's example, he has a particular temporal distributional property which together with his age determines that he was once a neonate, will be an old man and everything inbetween. Like the Lucretian, Cameron believes that we can ground truths about things that don't exist anymore by appealing to properties of the world as a whole. So the world has a certain distributional property that together with its age determines all the historical facts there are.

After articulating the notion of a dispositional property, Parsons (2004) goes on to argue that they can be used to provide an account of change that has advantages over existing approaches. However, he believes that a temporal application of distributional properties is plausible because he believes that time is relevantly like space. But for those who do not see time as like space the idea of temporal distributional properties may seem suspicious. For presentists, there seem in particular problem of accounting for how there can be distributional properties without an extended dimension for them to be distributed across. Such an application of temporal distributional properties is analogous to applying polka dots to a one dimensional line.

Cameron anticipates this objection and has a ready reply. He argues that the presentist should simply reject the intuition that in order to believe that an object is extended through time, one must accept the existence of the regions of time through which it is extended. In fact, Cameron claims, the presentist qua presentist is already committed to denying this premise. Some events and objects may be instantaneous, but most are extended through time. Thus the presentist must maintain the possibility of extension through non-existent 
regions of time in order for her position to be at all plausible. Given this prior commitment, the acceptance of distributional properties comes at no extra cost.

But Cameron's claim that the presentist is already committed to extension through nonexistent times seems to be based on a conflation of perdurance and endurance. Perdurance through time is a four-dimensionalist notion. Time for a four dimensionalists is a dimension relevantly like the three spatial dimensions, so objects are extended through time just as they are through space, with different temporal parts at different points in time. In contrast, presentists view objects as three dimensional and changing, existing completely at each moment. They cannot say that they are extended through time, but they do not need to. They can make the arguably more intuitive claim that they endure through it. So employing distributional properties does in fact commit the presentist to an additional cost of accepting a counterintuitive claim that she might otherwise avoid; namely, that objects and events can be extended through non-existent mediums.

There is a closely related objection that foists another unappealing commitment upon the presentist who adopts temporal distribution properties. The adoption's plausibility rests on the claim that temporal distribution properties are not reducible to non-distributional properties. If they were then it should be these more finely grained non-distributional properties that ground specific tensed truths. But note that in Parsons' original spatial example even if the polka dots do not supervene on non-distributional properties, they still supervene on more primitive distributional ones, like a portion of the surface having a particular distribution of redness or whiteness. Even if the distributional property being red polka-dotted is not reducible to non-distributional properties, a red polka-dotted surface must have some red parts. I see no reason why the temporal case should not be analogous. Even if time is not composed of unextended temporal points, temporal distribution properties will still supervene on finer grained temporal distributional properties, e.g. the distributional property Cameron instantiates that entails his aging from neonate to old man will supervene on properties like being a child being distributed across his sixth year of life, and the world's all-encompassing historical distribution property will supervene on distributional properties like the Triassic period's containing dinosaurs. But the presentist denies that the bearers of these finer grained distributional properties exist, and so she is committed to denying the supervenience. She must instead commit to taking coarsely grained temporal distributional properties as primitive, unlike their spatial counterparts. 
And even if the presentist is willing to accept these commitments, there is another, more fundamental problem with this approach. Cameron claims that the advantage that distributional properties have over the Lucretian ones is that are difference making properties, i.e. they meet the criterion that properties must determine something about their bearer's intrinsic nature to pass into our ontology. But here again, I think the question we asked of the Lucretian is pertinent: are these temporal distributional properties supposed to be intrinsic or relational? It seems implausible to say that they are relational properties because according to presentism there is nothing for them to relate to. And moreover, relational properties need not meet the difference making criterion, e.g. being taller than everyone else in the room determines nothing specific about the intrinsic nature of its bearer. But if they are supposed to be intrinsic properties then meeting Cameron's difference making criterion is insufficient for ontological admittance. After all, Sider's archetype of dubitability, dispositional properties, meet this criteria. The property being disposed to break determines something about its bearer, namely that it is not yet broken. As I argued in the previously section (5.2.1), intrinsic properties should supervene on their bearer's internal physical properties, or in Cameron's terminology on their intrinsic nature.

Cameron explicitly denies this, at least with regard to temporal properties. He claims that this requirement rules out legitimate properties that cannot be borne instantaneously but only over an extended period of time. Cameron offers no examples, but if there are such properties, and the presentist can find no way to accommodate them without denying that intrinsic properties supervene on their bearer's intrinsic nature, then so much the worse for presentism. Denying this supervenience is simply shifting the goal posts. Fortunately though I think the presentist can accommodate both claims: given a legitimate grounding of tensed truth (which I hope to outline in section 5.4) the presentist can account for necessarily persistent properties without denying that such properties supervene on their bearer's intrinsic nature. 


\section{3: Ersatzer Presentism}

Bourne (2006) opts for an approach that he calls ersatzer presentism. ${ }^{10}$ As the name suggests, in many ways this view parallels ersatzer accounts of modality. Ersatz times on this view are maximally consistent sets of unembedded (effectively simple present tense) propositions. Bourne treats propositions and by extension these ersatz times as abstract objects, though he maintains that the view is compatible with a reductive account of propositions. This principle of maximal consistency obviously generates many ersatz times that do not correspond to any way the world actually was or will be. To distinguish actual times from those that are merely possible, Bourne posits a primitive earlier than (E-) relation by which times are ordered into a temporal sequence. The present is the ersatz time that is physically instantiated and actual times are those sets that are E-related to the present or as Bourne puts it actually E-related. Thus we have in effect an ersatz B-series that can fulfil the truthmaking role in lieu of a concrete past and future. So the ersatzer presentist can ground tensed truths in the content of the ersatz times that are actually E-related. A proposition may be true in relation to ersatz times and if it is true in relation to a time that is actually E-related then we can say that it was true. And whereas the tensed properties view is committed to the dubious claim that tensed properties are intrinsic, by adopting an ersatz B-series the presentist to able to maintain that tensed properties are relations between present entities and an actually related ersatz time.

As Bourne readily admits, this E-relation is not the same as the genuine 'earlier than' relation. Whereas the genuine 'earlier than' relation relates (or at least purports to relate) concrete times, the E-relation relates sets of propositions. Nevertheless, Bourne argues, it is a direct representation of our ordinary 'earlier than' relation; by definition it shares all of its relevant properties; it is transitive, irreflexive, and asymmetrical, and thus relates abstract ersatz times in precisely the same way that the real thing relates concrete times. We should therefore not be concerned by the substitution of one temporal relation for another.

Oaklander (2010) is hesitant to buy this justification. He objects that the appeal to the mere replication of logical properties is an obfuscation that does not justify calling the Erelation "temporal". He points to the fact that the greater than relation shares all of these properties as well, yet is certainly not temporal. And if the E-relation itself is not temporal, then by extension, nor is the ersatz B-series that it is used to construct. So the E-relation and

\footnotetext{
${ }^{10}$ This approach is also suggested by Davidson (2003) and defended by Crisp (2007). But for brevities sake I will focus on Bourne's exposition.
} 
ersatz B-series fail to adhere our ordinary conception of what temporal talk is all about. As Oaklander goes on to note, our understanding of the phrase earlier than "is grounded in our experience of one event occurring before another, and not by contemplating a relation between abstract objects."

In a similar vein, one might object on the grounds that the fact that a particular ersatz time is E-related to the present seems to be completely ungrounded in the prior concrete realisation of that time. The two correspond, but merely by stipulation. The ersatz B-series reflects what actually happened, but it does not reflect it because it happened; i.e. there is no causal relation between real concrete events occurring and the ersatz B-series having the E-relations that it does. So ersatzer presentism has the absurd implication that there were dinosaurs is true not because dinosaurs once existed, but because an abstract set of propositions is appropriately related to an abstract representation of the present.

I think these objections point to an underlying disanalogy between time and modality. Linguistic ersatzism has prima facie appeal because the claim that modal matters come down to conceptual relations is plausible. Whereas these implications of ersatzer presentism seem absurd because the corresponding claim that temporal matters come down to conceptual relations is implausible. Claims about the past are claims about the world itself, not our conceptual representation of it. I discuss this disanalogy between time and modality in more detail in chapter six, wherein I compare the plausibility of temporal and modal ontological primitivism. First though, I end this chapter with an exposition and defence of the response I think the presentist should make to the truthmaking challenge.

\section{4: Revisionary Presentism}

I believe the presentist can and should appeal to exactly the same truthmakers for tensed truths as the four-dimesionalist. She can do this by revising the truthmaker principle to allow for truthmakers that did or will exist, thereby denying that tensed expressions require existing truthmakers. This approach is simple and I think a natural consequence of taking tense seriously, properly construed. Certainly if one is already committed to the idea that the totality of existence is unchanging then the intuition that truth supervenes on what exists is a strong one. But if one thinks that tense is a feature of reality itself and thus that the whole universe is dynamic, then the idea that truth supervenes on what exists does not seem at all obvious. If tense is to be taken seriously in this way then it seems that the natural answer to 
the truthmaker question is to simply say that what makes it the case that (for example) 'there were dinosaurs' is simply the dinosaurs that did exist.

Given how naturally this response falls out of presentism, I find it surprising how little endorsement or even consideration it has received in the literature. Most presentists instead resort to elaborate theoretical contortions in order to accommodate the standard version of the truthmaking principle. There are a few recent exceptions however. Keller (2004: 92-93) in passing briefly mentions the possibility but immediately rejects it; Gallois (2004) suggests it as part of a symposium on Sider's Four-Dimensionalism (2001); Sider (2004) in turn offers a brief rebuttal; Armstrong (2004: 147) attributes the idea to John Heil on the basis of personal communication, and considers it the presentists best bet but argues that it still faces some fatal objections; Westphal (2006) takes a revisionary line as part of what he calls the common sense view of future-tensed semantics; Tallant $(2009,2010)$ has argued that a revisionary response is appropriate for a variety of challenges grounding poses; and Sanson and Caplan (2010) have defended this revisionary line of response in the temporal case specifically.

It should be emphasised that revisionary presentism is not an appeal to propositions as truthmakers. It is easy when explaining this position to slip in loose talk which may give this impression. Saying things like "there were dinosaurs is true because dinosaurs did exist" may quite understandably be interpreted as claiming that the tensed existential proposition dinosaurs did exist is acting as a truthmaker. Obviously this strategy would not solve the problem but merely push it back; we would still need truthmakers for the tensed existential propositions themselves.

I would also like to emphasise that I am not proposing the endowment of past and future entities with any sort of Meinongian quasi-existence; I do not want to suggest that there are dinosaurs that do not exist. Such a move might not be entirely without merit. A restricted Meinongianism that posits non-existent past and future entities might avoid the main failing of its unrestricted cousin. It is often charged that the distinction between existence and being does not make sense; that the notion that there really are non-existent unicorns etc. is unintelligible. But I think we can make some sense of the claim that even if past and future objects do not exist, they are still a part of reality in a way that things which never were or will be are not. But there is a problem; adopting this Meinongian approach makes presentism start to look indistinguishable from A-theoretic eternalism, according to which the past and future exist but there is an objective present that moves through time like a spot light. The 
only difference seems to be in the way words like existence and being are used. As such, I doubt many presentists would find this restricted Meinongian approach attractive.

What I am proposing is that the dinosaurs and other past entities, relations and events can themselves act as truthmakers. One might object that there simply are no dinosaurs in the presentist ontology. But this is precisely the point of presentism: there aren't but there were. The approach I am proposing consists in revising of the truthmaker principle to accommodate this point. This may seem an ad hoc response to some. Armstrong's (2004: 147) first response to the view is to notes that this "re-doing of truthmaker theory" seems to him "painful and artificial". In response, I would like to press and clarify the point that I think that this theory falls naturally out of the presentist's conception of reality.

The presentist qua A-theorist endorses the ethos "taking tense seriously" by taking tensed operators as semantic primitives, unanalysable in tenseless terms. I think that she should qua presentist also take tense seriously in an ontological sense, i.e. she should take time or some temporal feature of the world as an ontological primitive. As it happens I suspect most presentists do, at least implicitly, as I have a hard time imagining how as presentists they can hope to accommodate change without doing so (I have more to say on this toward the end of this section). There are a number of ways in which one might be an ontological primitivist with regard to time. ${ }^{11}$ If the Lucretian, for example, takes her tensed properties to be primitive (as I argued she must in section 5.2.1), this would qualify her as an ontological primitivist. But Lucretianism obviously doesn't lend itself to the revision of the truthmaker principle I am advocating. The kind of ontological primitivism that I would endorse-and that best captures what I understand to be the common sense intuition underlying presentism-posits tensed modes of being that are irreducible to one and other. Call this tensed modes of being primitivism (TMB primitivism). So in addition to the kind of being that captures the way things are, The primitivists broad ontology (i.e. her conception of the nature of being) includes two further primitive modes of being: past being and future being. Dinosaurs have being only in the former mode, moon colonies only in the latter. There are no dinosaurs or moon colonies, but there were dinosaurs and will be moon colonies.

\footnotetext{
${ }^{11}$ Another option might be to posit irreducibly tensed facts. But while tensed facts might not be reducible to tensless facts, given that facts are complex composites, it would seem that they should inherit their tensedness from one or more of their components somehow. So if fact is irreducibly tensed we should expect that it comprises a temporal property or relation or something. So as composites, facts are not suitable candidates for ontological primitives.
} 
Given these distinct modes of being, past and future existence cannot be reduced to the ordinary mode of existence that the present has.

With this ontological framework in place, we are now in a position to state the revised truth making principle that I believe the presentist should endorse. Call this the revised Boolean supervenience thesis:

(RBST) Every truth $t$ either has a truthmaker in the tensed mode of being corresponding to $t^{\prime}$ s tense (i.e. past being if $t$ is past tensed, present being if $t$ is present tensed or future being if $t$ is future tensed) or is some complex Boolean function of propositions that each either have a truthmaker in the appropriate tensed mode or would have a truthmaker in the appropriate tensed mode if true.

TMB primitivism is not independently sufficient for this revision of the truthmaking principle, but it does warrant the move. The legitimacy of this warrant rests upon the general principle that we should widen the base of the truthmaking principle to accommodate one's conception of reality. If this general principle is in need of motivation, it can be found in an examination of function truthmaking is supposed to serve. As I noted in chapter three, truthmaking is supposed to capture the intuition that truth is grounded in reality by tethering our semantics to our ontology. But grounded in reality only means grounded in what exists if reality only consists in what exists. Here it is worth distinguishing between two senses of the term ontology. In the first, narrow sense of the word, an ontology is simply a list of things one is willing to admit the existence of. But there is another sense in which we can use the term. In this broader sense ontology concerns not just what exists but the nature of existence. How we answer the first question depends on how we answer the second. So the starting question should not be "what exists?", but instead "what is the nature of existence?", and the presentist answers this more fundamental question quite differently than the eternalist does. For the eternalist there is only one primitive temporal mode of being, for the TMB presentist there are three. So the truthmaking principal in its standard form is phrased in such a way as to presuppose eternalism and thus beg the question against presentism. It is not a self-evident truth that truth supervenes on what exists; we must assume that the existential facts do not change. But we cannot simply assume this without first giving some reason for rejecting the presentist's conception of reality. And if we start out with the assumption of presentism, it seems obvious that the standard truthmaking principle is simply false. So we would need to justify eternalism in order to justify the standard truthmaking principle. 
Sanson and Caplan (2010) provide a reasonably extensive defence of revisionary presentism. The core of their argument is the claim that the approach is more plausible than the alternatives because it is the only one that provides appropriate explanations for what makes tensed statements true. Recall their objection to Lucretianism, discussed earlier in this chapter (section 5.2.1). Lucretianism has the implausible implication that the proposition Arnold was pale is made true by the present-tensed fact that Arnold instantiates the tensed property having been pale. Contrast this with the more plausible primitivist explanation: Arnold was pale is true because Arnold previously instantiated the property being pale. So Lucretianism and the tensed properties approach in general, implies that contrary to our intuitions, past-tensed truths are grounded in the present instantiation of tensed properties. In contrast, the explanation that revisionary presentism gives-that past-tensed truths are grounded in the past instantiation of present-tensed properties-accords with our intuitions.

The reductionist and ersatz lines also offer deficient explanations for tensed truths. The reductive presentist claims that Arnold was pale is true (if it is determinately true at all) because it is determined by the way the world is now. This might in some cases be an appropriate explanation for one's belief that Arnold was pale but it is not an appropriate explanation for the truth itself. The ersatzer presentist claims that it is true because of an abstract e-relation relation between sets of propositions. Yet, as I noted above, this Erelation has bears no relation to the actual past events that would allow us to say that an ersatz time is E-related to the present because it represents what actually happened. At best the ersatzer presentist can say that the ersatz past and actual past happen to correspond, but only by stipulation. In contrast the revisionary presentist points to the actual past itself. So the she has an advantage over all of the presentist alternatives we have considered in this chapter in that she alone can provide intuitively plausible explanations for tensed truths.

There is another advantage to this revisionary approach that I am somewhat hesitant to discuss because the nature of the subject makes it is difficult to do so in a clear and rigorous way. Nevertheless, I think it is worth trying because if the point is intelligible, it provides strong motivation for the kind of temporal primitivism I outlined above.

Presentists sometimes claim that one of the advantages of their position is that it provides the most intuitive account of change; theirs is a dynamic world with entities and events coming in to and out of existence. But under closer examination, it is not at all obvious how change fits into this conception of reality. The eternalist can account for change in terms of variation across the temporal dimension of her four dimensional universe. But all that the 
presentist includes in her ontology is a three dimensional world and hopefully some true propositions about other times. Nothing in this picture constitutes time or change. ${ }^{12}$ I think for the presentist to account for change, time must be in some sense ontologically prior to existence. Call this the temporal priority thesis. It is difficult to explain exactly what I mean by ontologically prior here, but hopefully the following few points will give some impression of what I am trying to get at. I do not mean to say that existence is existentially reducible to time; obviously this would make no sense. I am using ontological here in the broader sense I distinguished above; pertaining to the nature of existence rather than the question of its extent. By prior here I mean to say that in an explanation of how reality is built, the temporal manifold is more fundamental than existence, not in the sense that existence is composed of time, but that existence is somehow built on top of time. Whereas for the eternalist, time emerges as a consequence of what exists (viz. the fabric of space-time), for the presentist time does not depend on what exists, but rather partially determines it. For the presentist everything that exists is embedded in a temporal manifold.

Of course much of this picture is metaphorical. Existence is not literally built upon or embedded in anything. I suspect that the use metaphor here is to some extent unavoidable. It may be that natural language is simply unequipped to adequately deal with such questions about the nature of existence itself. Though on the other hand, I would not completely dismiss the possibility that there might be a way to explain this idea with precision and clarity. But for want of such a precise explication, it may be charged that the idea of time's priority to existence is simply unintelligible. I have no argument to make in response to this potential charge; as an eternalist I am open to the possibility that it is indeed unintelligible. But I think that something like this idea of temporal priority is essential to the plausibility of the presentist's account of change. So if the idea I am gesturing at is truly incoherent then I think presentism falls with it.

If I am correct that temporal priority is essential to the plausibility of presentism, then this fact is to the advantage of revisionary presentism, or more precisely, to the advantage of the TMB primitivism that lends itself to the revisionary approach. For the other varieties of presentism I have discussed in this thesis, truths about other times are ultimately grounded - in one way or another - in facts about what exists. But if time is prior to existence then we should not expect truths about the past to depend upon what exists in the present.

\footnotetext{
${ }^{12}$ I would like to acknowledge Simon Keller for bringing this problem for presentism to my attention.
} 
The explanation for past truth should point to something deeper than what exists, just as the TMB primitivist points to alternative modes of being.

I should emphasise that I am not saying that there is a necessary connection between temporal priority and TMB primitivism in either direction. One could plausible adopt TMB primitivism without accepting the temporal priority thesis or my claim that it is essential to the plausibility of presentism, perhaps on the grounds that it offers a common sense interpretation of presentism that overcomes the obstacles its competitors stumble upon. Likewise there may well be other forms of presentism or temporal primitivism that fit with temporal priority just as well or even better than TMB primitivism. All I am saying is that if the temporal priority thesis is right then of the alternatives considered in this chapter, TMB primitivism is the only one that is at least looking in the right place for an explanation of tensed truth. If on the other hand, you do not buy the temporal priority thesis, I think the other advantages of Revisionary TMB presentism offer ample reason for preferring it to the available alternatives.

So to summarise this section so far, the revisionary presentism I am endorsing proposes a variation of the truthmaker principle that allows truthmakers that do not exist but did or will do so. This revision falls naturally out of a particular kind of temporal primitivism that I think presentists should endorse. The revisionary approach has two major advantages over its rivals. First, it offers intuitively plausible explanations of tensed truths; and second, it is more in line with the temporal priority thesis that is required for presentism to plausibly account for change. In the remainder of this chapter I defend revisionary presentism against some of the objections that have been levelled against it in the literature.

\subsection{1: An Internal Problem}

Returning to Armstrong's (2004: 147) critique, after accusing the revisionary presentist of ad hocery, he goes on to argue that her theory faces an "internal problem":

"[Revisionary Presentism] urges that although <Caesar exists> lacks a truthmaker, and is not true, yet that proposition was once true and did have a truthmaker at some time... What of the proposition <this proposition was true>? It must certainly be counted as true by the presentist. What is its truthmaker? It would seem it does not have one, because there is nothing in the present in virtue of which it is true."

I take it that by "this proposition" here, Armstrong is referring to <Caesar exists>. The objection seems to be that if the proposition <Caesar existed > is true because <Caesar exists> was true then to establish a grounding for the original proposition we must first establish a 
grounding for $<<$ Caesar exists $>$ was true $>$. But of course grounding this proposition is no easier than grounding the original one. Nothing in the present makes it true, and to appeal to Caesar himself would take us full circle back to where we began.

Where I think this objection goes wrong is in its initial assumption that the truth of the tensed proposition <Caesar existed> is grounded in past truth of the present tensed proposition Caesar exists. It seems to me that Armstrong has a slightly different theory that I tried to distance myself from earlier. As I stressed, the revisionary approach I am advocating in this paper does not claim that tensed truths are grounded in other propositions. <Caesar existed $>$ is grounded in the past existence of the concrete Caesar.

\subsection{2: A Bridge to Nowhere}

Armstrong's next objection is supposed to undermine any attempt to provide truthmakers for presentism of any variety. He notes that presentism requires relations between existent and non-existent entities, and these relations are "ugly additions to our ontology." Bigelow (1996) revises and addresses this line of argument. He first considers the possibility of rejecting the premise that all relations are existence entailing. Some certainly seem not to be, at least on their face: for example, that 'King Kong is bigger than me' is true, even though King Kong doesn't exist and I do. But ultimately he argues that even if it is conceded that some relations are not existence entailing, causal relations surely are and this is enough to provide a sufficiently powerful version of the argument.

So instead of disputing this premise, he argues, in line with his Lucretian response to the truthmaker problem, that causal relations are actually relations between present entities and primitive tensed properties. I have a scar on my head that was caused when I ran into the corner of a table as a child. According to Bigelow, the causal relation here is not between a non-existent past head banging and an existent scar, but is a relation between the existent scar on my head and an existent property of the world being such that I banged my head as a child.

But, of course, this line of response won't work if we reject primitive tensed properties, as I argued we should. Instead, the revisionary presentist should simply deny the claim that causation is existence entailing, except insofar as it entails that the objects did, do or will exist. To be the cause of the scar on my head, it is enough that my head banging incident simply did occur. Again this may seem a cop out at first glance, but similar arguments can made here as were made above. The response is a natural consequence of taking tense 
seriously in an ontological sense, and to expect the presentist to provide only existing relata for cross-temporal relations is question begging. If the presentist can employ past facts as truthmakers there seems no reason why she should not employ those very same facts as relata for cross temporal relations. And it is also worth noting that this also allows her a plausible account of tensed properties, both Lucretian and distributional. Whereas the tensed property presentists were forced to take them as intrinsic primitives, the revisionary presentist can account for them in reductive relational terms.

\subsection{3: Falling Short}

Keller (2004) provides a thorough exposition of some of the possible strategies a presentist might take in response to the truthmaking challenge. While he does not explicitly consider the revisionary line I am defending here, he does make some remarks in passing that are relevant. In considering how the presentist might provide truthmakers for the proposition 'the Tower was on the Thames' Keller (2004: 93) notes:

"It's not enough to say that the proposition's constituents did exist and did stand in a certain relation, because that would only show that the proposition did exist. The Tower was on the Thames is true now."

This idea that Keller quickly dismisses looks like the revisionary line of response under consideration. Keller seems to be suggesting that all we can get from the past existence of truthmakers is the past truth of present tensed propositions, not the present truth of past tensed ones that we want. However, I can see nothing of consequence that follows from this distinction. Any plausible temporal logic will allow us to straight forwardly infer the present truth of a past tensed proposition from the past truth of a present tensed one; if it is the case that the Tower is on the Thames was true then it must also be the case that the Tower was on the Thames is true. Of course I argued above that truthmaking is not closed under logical entailment. But truth is, so if $x$ grounds $p$, and $p$ entails $q$, then we know that $q$ is true and therefore must have a truthmaker, even if it is not necessarily $\mathrm{x}$. Our primary concern here is with showing that there are truthmakers for tensed truths; we do not need to pinpoint the truthmakers exactly. (As it happens though, I think the fact that the Tower and Thames did stand in a certain relation is a perfectly legitimate truthmaker for both of the propositions in question.)

\subsection{4: Collapse}

It is sometimes charged that the debate between presentism and eternalism is merely a verbal disagreement. These sceptics argue that despite both parties' sincere belief that there 
are substantial and incompatible differences between the two positions, they equivocate on some basic piece of terminology and so are really just talking past one and other. One concern presentists might have is that revising the truthmaker principle might remove whatever substantial difference there is, thus validating the sceptics concerns. By allowing herself metaphysical access to past entities and their properties, the presentist avails herself of the eternalist's answers to a whole host of objections. But if there is no substantial difference remaining then revising the truthmaker principle effectively collapses presentism into eternalism.

Torrengo (2011) argues someway along these lines. While not arguing for a complete collapse into eternalism, he argues that what I have called revisionary presentism is susceptible to the sceptical charge that it is indistinguishable from eternalism, at least as far as matters of what Torrengo (taking after Sanson and Caplan [2010]) calls "ideology" are concerned. Matters of ideology concern the way things are (in particular the instantiation of properties) and are contrasted with matters of simple ontology.

Torrengo's hypothetical sceptic argues that for there to be a legitimate ontological debate, the two parties must agree on fundamental notions of existence and instantiation. Without an agreement on these central and fundamental concepts, we have good reason to suspect that the two parties are using different sentences to say the same thing. Torrengo stresses that, in general, he denies the sceptic's conclusion that eternalism and presentism are merely verbal variants of the same thesis. He thinks that most presentists and eternalists do share a common notion of fundamental instantiation. But he claims that where a party in the debate changes the sense of a theoretical issue (in this case: the truthmaking challenge) we have reason to doubt that they are in genuine disagreement. He proposes the following antisceptical constraint on any genuine form of presentism or eternalism:

ASC. "An anti-sceptical stance toward the ideological difference between presentism and eternalism is not compatible with construing a theoretical question, which the opponent understands in terms of fundamental instantiation, in terms that do not require the answer to imply fundamental instantiation"

By denying that truth must be grounded only in existing entities and the properties and relations that they instantiate, the revisionary presentist is construing the truthmaking question in different terms to the eternalist. She thereby violates ASC, and therefore should not be considered a genuine presentist.

Torrengo makes no claim that his argument is strictly valid. Nevertheless there are invalid inferences at a couple of points that while perhaps plausible individually, when taken 
together tarnish the persuasive force of the overall argument. The sceptical argument itself could use more explanation than Torrengo offers. A lack of agreement on a single terminological point in itself does not obviously entail or even suggest that the two parties are in overall agreement. In light of this, the adoption of the ASC constraint on the basis of this sceptical argument seems a little heavy handed. It seems Torrengo is keen to convict revisionary presentism of fraud on the basis of potential susceptibility to an argument that has not been fully made.

More importantly though, the revisionary presentist does not disagree with the eternalists conception of fundamental instantiation. Like any presentist, she shares the eternalist's notion but applies it only to present entities. She does disagree however that this is the only fundamental mode of instantiation. As noted above (section 5.4), revisionary presentism rests on a kind of temporal primitivism which posits three primitive temporal modes of being. So past existence is not reducible to present existence. Taking tense seriously in this way has the same implications for ideology as it does for ontology: past and future instantiation are primitive modes of instantiation, irreducible to present instantiation. So changing the sense of a theoretical issue (viz. revising the truthmaking principle) does not necessitate holding a different notion of fundamental instantiation.

I do think that when construed very broadly, Torrengo's point is correct: this revision of the truthmaking principle does draw presentism a lot closer to eternalism. But as long as the there remains some substantial difference, $I$ do not think that this is necessarily an undesirable result. We should not be concerned if the views turn out to be quite similar, indeed I think we should expect as much. The difference between the two positions is quite subtle; neither view is particularly outlandish (though in my opinion presentism does start to look a bit crazy when it bends over backwards to accommodate the externalist's truthmaking demands) and both agree on the vast majority of the facts. Moreover, in this case at least, the presentist should be pleased to narrow the gap. Revising the truthmaker principle avails her of many advantages of eternalism, in particular a coherent and intuitively plausible response to the truthmaking problem and other related problems (like accounting for crosstemporal relations and non-instantaneous events) without sacrificing any of the advantages of presentism (she can maintain an A-theoetic explanation of the passage of time and our subjective experience of it, etc.). Of course this preservation of A-theory does bring with it disadvantages too, most notably the revisionary presentist still has a hard time reconciling 
her view with special relativity. But this difficulty does at least indicate that revisionary presentism is a substantially different position to B-theoretic eternalism.

But what about A-theoretic eternalism? These advantages and disadvantages stem from the preservation of an absolute present, not an exclusively existent one. Perhaps presentism still collapses completely into eternalism, only into its A-theoretic variation. For most presentists I suspect that this is just as undesirable as a collapse into full-blown B-theoretic eternalism would be; perhaps even more so. Fortunately though, there are substantial differences in this case too. Again, A-theoretic eternalism is subject to objections that pose no threat to revisionary presentism. Perhaps the most daunting objection facing A-theoretic eternalism concerns its epistemic plausibility. It is surely true that the present is the moment you occupy as you read this. But how do you know that you are in the present? For the Btheorist answering this question is not a problem because temporal presence is reflexive. So we always occupy our present by definition. Likewise the presentist has an easy answer available to her: because everything that exists is present, the fact that we exist entails that we must be present. But neither of these answers is available to the A-theoretic eternalist. She claims that presence is an absolute predicate, so the claim that we are present is not simply true by definition. And she claims that there are other non-present times that exist, so the fact that we exist does not entail that we are present. Universal scepticism aside, we can easily discern that we exist, but the fact that we are present in itself seems indiscernible. There seems nothing to tell apart present and non-present existence. So for example in the distant past of the A-theoretic eternalist's world, an existent Socrates is thinking he is in the present moment, and you believe the same thing. At least one of you must be wrong but there seems no way of deciding who. If objective presence is indiscernible even in principle, there seems to be no advantage in positing it at all. But now note that this objection does not trouble the revisionary presentist. She can appeal to the same answer as any other presentist; we exist therefore we are present. This suggests that revisionary presentism is a genuine form of presentism, not eternalism - A-theoretic or otherwise - in disguise.

There is another reason for thinking that the revisionary approach does not collapse presentism into eternalism. Sider (2001: 15-16) considers and rejects the sceptical hypothesis. One way the sceptic might argue is that the eternalist uses the existential quantifier tenselessly, so when she says "a dinosaur exists" this can be translated into presentese as a disjunction of tensed quantifications: "there did, does or will exist a dinosaur". Once we translate as appropriate, it seems the disagreement vanishes. But Sider 
notes that there are cases concerning the existence of cross-temporal sets where the disagreement remains. The eternalist admits the existence of the set containing a dinosaur and a computer. But, assuming that a set's existence requires the existence of its members, the presentist will deny this claim even when it is translated into tensed language. There is no such set presently and there never was or will be, because at no time did dinosaurs and computers co-exist. And even if sets do not require the existence of their members to exist themselves, the hypothetical fact that presentists and eternalists would disagree if they did suggests that there is a substantial difference between the two views. Revising the truthmaker principle does not in any way threaten this distinction.

\subsection{5: Explosion}

Sider (2001: 41) claims that to take tense operators as primitive is cheating because they fall on the wrong side of his categorical-hypothetical distinction. Given that the revisionary approach takes tensed operators as primitive, both semantically and ontologically, Sider would no doubt reject the revisionary approach on these grounds. But as I argued above (section 5.2.1) Sider's demand that we only appeal to how things "actually are" begs the question against presentists and actualists. If he wants his cheating accusations to be compelling, he needs to find another basis for his distinction.

It seems to me the main point Sider is making with his cheating accusations is that his target is in the same camp as other disreputable positions and is guilty by association. Along these lines he (Sider 2004) argues that this primitivist strategy is equally available in response to any demand for truthmakers. Heathwood (2007) makes this link between cheating and explosion explicit in objection to Westphal's (2006) proposal of the revisionary approach, arguing that it is just as available to the actualist, but in the modal case it is obvious that the move is a cheat. Sider raises this explosion objection in response to Gallois's (2004) proposal of the idea. Gallois notes that the revised truthmaking principle (or as he calls it the presentist truthmaking principle) still rules out all of the kinds of positions Sider labels ontologically dubious, like brute dispositions, counterfactuals or modal claims. But, Sider replies, while it is true that as it stands the revised truthmaking principle does rule out these dubious positions, there seems to be no principle stopping us from making further revisions to allow them in. If we can say that 'there were dinosaurs' is made true by dinosaurs that did but do not exist, why not take a similar line regarding other positions challenged by the truthmaker principle? What would stop us from saying that 'the glass is fragile' is made true by the broken state the glass is disposed to exist in, or we could say that 'unicorns are possible' is 
made true by a unicorn that might exist? And if the revisionist strategy is indiscriminately applicable, then truthmaking is trivial. It seems to Sider that the only principled place to draw the line is around existence simpliciter.

One option here would be to bite the bullet and accept that truthmaking objections carry no weight. This is essentially the line that Tallant $(2009,2010)$ defends. But I would hope to avoid this implication. Throughout this essay I have warned repeatedly about the danger of being too undiscerning with regard to the truthmakers we allow, like a zealotrous doomsayer, raving about the impending perils facing us if fail to mend our promiscuous ways (though I hope this analogy doesn't fit too snugly!). It would be a terrible hypocrisy on my part if the approach I endorse should succumb to this objection without a rigorous defence. In the next section I put forward the case that there is a principled reason for accepting the primitivist strategy in the case of tensed truth but not in other cases like dispositional, counterfactual and (importantly for the ultimate aim of this thesis) modal truth. The key difference is that presentists take tense to be a fundamental feature of reality, whereas actualists cannot plausibly maintain the corresponding modal claim. 


\section{Chapter 6: Revisionary Actualism}

On the face of it the case for revisionary presentism that I made in the previous chapter may seem to have a fairly straight forward modal parallel. To briefly recap the case, I argued that to accommodate the presentist conception of change the presentist should adopt what I think is a common-sensical kind of temporal primitivism that posits three fundamental modes of being (TMB primitivism). Given this view, the standard formulation of the truthmaking principle (i.e. that demands existing truthmakers) begs the question. The presentist is justified in revising the standard principle that truth supervenes on what exists, because what exists fails to fully capture her conception of reality.

The ostensive parallel argument would go something like this: Just as the presentist sees the world as changing, the actualist sees the world as a contingent; the sum total of what exists could have been otherwise (in contrast, according to modal realism, reality as a whole - i.e. the multiverse - is as it is necessarily). So she should adopt a version of modal primitivism that posits an alternative primitive possibilist mode of being: merely possible being in addition to actual being. The actual world exists in the latter mode and all other possible worlds exist in the former, i.e. they could have existed but don't. Call this possibilist modes of being primitivism (PMB primitivism). A modal primitivist of this ilk would be justified in charging that the truthmaking objection is question begging, and thus adopting a revisionary response. She should revise the truthmaking principle such that truth supervenes on what exists or could have existed. So, $\diamond p$ iff there is or could have been a truthmaker for $p$. And $\square p$ iff there must be a truthmaker for $p$. And we can analyse a possible world simply as a world that is or could have been.

I accept that for PMB primitivists, a revisionary approach would be an appropriate response to the truthmaking challenge. However, in the next section I put forward an argument that this kind of modal primitivism is untenable. The central premise of the argument is that we are only causally related to that which is actual, and never to the merely possible. But note that the corresponding temporal premise does not hold; we are causally related not just that which is present, but also to that which was and will be. This disanalogy means that the argument against modal primitivism does not have a temporal parallel. Thus the temporal primitivism that underwrites revisionary presentism is tenable, whereas the modal primitivism that underwrites revisionary actualism is not. 
(The arguments in this chapter are framed in terms of modes of being primitivism, as this is the kind of primitivism that is my primary concern. But somewhat incidentally, I think that with a little reworking, these arguments may well apply more broadly to modal and temporal primitivism in general.)

\section{1: Against Modal Primitivism}

Sider (2003) provides a possible reason for wanting to avoid ontological modal primitivism. He notes a similarity between our epistemic relations to necessity and causation:

\footnotetext{
"It is easy to get into a frame of mind according to which modal notions should not be taken as "rock bottom", ontologically speaking. The frame of mind is not unlike Hume's when he confronted causation. One can see the prior event, and also the later one, but where is the causation? Likewise: I can see that this colored thing is extended, and indeed that all colored things I have examined are extended, but where is the necessity, that colored things must be extended?"
}

Sider goes on to note that there are metaphysical reasons for seeking a reductive account of modality (i.e. his cheating argument rehashed) but it is the epistemic argument that I want to focus on. The key point here is that we are unable to observe necessity itself; we can only ever observe the world as it actually is. Ultimately, we learn about the features of the world itself a posteriori, either by direct observation or by observation of evidence. So if as the PMB primitivist claims, necessity is grounded in constancy across the way things could have been then to discover necessary truths would require us to observe, directly or indirectly, things in this alternate mode of being. But observation requires causal interaction, and we cannot causally interact with the merely possible. We cannot therefore obtain empirical evidence for the necessity of a proposition of predicate.

So we cannot learn about the ways things might have been being by empirical means. So if, as the revisionary actualist supposes, ways things could have been are primitive features of reality, we would have no way of discerning them, even in principle. It is utterly redundant to posit features of reality that are completely epistemically inaccessible. And of course whatever modality is, it is something we do know at least something about, so it cannot be a causally isolated feature of reality.

\subsection{1: Ostensive Cross-World Causation}

There are certain expressions that, taken at face value, appear to provide counter examples to the claim that we are causally isolated from the merely possible. For example: 
- The new possibility of predation caused the evolution of various defensive adaptations.

- The low ceiling made upward growth impossible, and this caused the plant to branch out.

- The drought made growing food impossible, which caused wide spread starvation.

These seem like expressions that in the right circumstances could be true. And if taken literally, they express propositions that claim cross-world causation, viz. the merely possible affecting the actual. But I do not think that we should take them literally. It strikes me that the real causal processes involved in the events these sentences describe involve only nonmodal causes. In each case there is a more accurate and detailed explanation to be had that reflects the individual causal process involved. So in the first example, there is a story to be told about genetic mutations and the success of various traits etc., in the second there is a story to be told about the biochemical processes of a plant searching for sunlight, and in the third there is a story to be told about people failing to grow food etc. These more exact explanations do not need to employ this kind of cross-world causation talk. The purpose of doing so seems to be to provide some explanatory advantage, either in terms of economy or generalisability.

There is another kind of ostensive cross-world causation that requires a slightly different explanation. In certain cases involving agency it seems that there is a particular agency-based explanation to be had. Consider the following examples:

- The possibility of winning caused her to participate.

- The inevitability of defeat caused her to give up.

I contend that both statements really express propositions about mental states, i.e. in both cases it is actually the belief or perception of possibility or inevitability that is doing the causal work. So statements of this kind express propositions of the form the propositional attitude that $p$ caused $q$, where $p$ is a modal clause. Reinterpreted in this way both propositions still retain their modal content but it is embedded the scope of a propositional attitude, and the mental representation of possibilia does not imply their reality.

So given these interpretations, the examples above do not constitute counterexamples to the claim that we are causally isolated from the merely possible. In fact it seems that such examples support the alternative hypothesis that modality is a feature of the way we represent the world, not of the world itself. If claims about cross-world causation are really 
explanatory shortcuts or claims about the causal efficacy of various mental representations of possibilia, this suggests that they are conceptual tools we use to explain and navigate the world. Of course, these explanations cannot in themselves constitute a rebuttal of these ostensive examples of cross-world causation. As such they are obviously question begging. However, the availability of these alternative explanations provides an option for those who find the concerns raised above about the epistemic plausibility cross-world causation outweigh the prima facie merit of taking such expressions literally.

\subsection{2: Inducing Modal Truth}

Sider's comparison of necessity with causation (quoted above in section 6.1) is perhaps an unfortunate choice. As I understand it, Hume's point regarding causation is that it is not the necessary connection we take it to be. Nevertheless it seems the observation that B has always followed $A$ seems like reasonable inductive evidence that there is some sort of special relation in place, and that this relation is a feature of the world itself. Perhaps something similar can be said about the primitive modes of being that the modal primitivist posits; we cannot observe them directly, but we can maybe infer their presence inductively. After all, there are plenty of examples of modal facts we do learn a posteriori. We learned that it is possible to break the sound barrier and impossible to travel faster than the speed of light, for example.

To explain cases like this it is useful to draw an analogy with another of Hume's famous observations. There is a kind of difficulty in inferring necessity from actuality that parallels the fallacy of inferring norms from descriptions. Whenever we infer an 'ought' from an 'is' we must presuppose some other normative bridging proposition. We certainly do learn new moral facts a posteriori, but their normative content is always derived from a more fundamental a priori normative truth. We learned that smoking tobacco leads to cancer (and with it unnecessary suffering) and this empirical fact entailed the normative truth that one ought not to smoke. But the entailment requires the normative bridging truth that cetera paribus suffering ought to be avoided. It is from this bridging premise that the conclusion inherits its normative content. Likewise, we cannot infer conclusions about the way things must be from a posteriori premises that are exclusively about the way things actually are. Such inferences require a modal bridging proposition which is established (or at least brought to the table) $a$ priori. These bridging premises bequeath their conclusion its modal content. 
The most salient of a posteriori necessities are nomic necessities. So for example, when we conclude that it is impossible for anything to exceed the speed of light because to do so would contradict relativity theory, we tacitly appeal to the law of non-contradiction as a bridging premise. One might argue that the laws of nature are necessary truths that we discover a posteriori, by abduction from observations of actual consistency. But really, these laws are generalisations about the structure of reality. Certainly they are nomological necessities, but this just means they are necessary given themselves, and is no more interesting than the fact that my belief that it will rain tomorrow makes rain tomorrow a doxastic necessity for me. Both are made true by the a priori bridging premise that 'necessarily $(p \rightarrow p)$ '.

More generally, actual consistency does not imply necessity. One might however argue that it provides inductive evidence for necessity. Of course there are plenty of cases where things that are consistent are not necessary (e.g. contingently, every human that ever was or will be is less than 10 feet tall), but then induction is not supposed to be $100 \%$ reliable. Such cases are still a problem however. The fact that we know that these things are contingent despite their consistency demonstrates that we have some independent means of deciding what is contingent and what is necessary. If the basis of our knowledge of necessity were in consistency alone then we would not be able to make such judgements. Furthermore, a good inductive inference requires a representative sample, but it can hardly be argued that the actual world is representative of all of modal space (at least not without some independent method of discovering the content of other possible worlds, which would undermine the need for the inductive inference in the first place).

\subsection{3: A Posteriori Necessities}

So much for nomological necessity. But what of the a posteriori metaphysical necessities that Kripke (1972) brought to our attention? When we learn through observation that the Hesperus is Phosphorus, that water is $\mathrm{H}_{2} \mathrm{O}$ or that Elizabeth Windsor was born of gametes $\mathrm{x}$ and $y$, we discover a necessary truth a posteriori. Such cases show we can in fact discover even metaphysical necessities by observation, and it is not clear that there are a priori bridging premises that we can point to as the root of the necessity. Certainly there a priori premises that concern identity involved in the inference (e.g. 'if $(A=A)$ then necessarily $\left.(A=A)^{\prime}\right)$. But it seems that the initial observation that $A=B$ (e.g. Hesperus is Phosphorous) itself is inherently modal. 
As Kripke makes clear, rigid designation plays an essential role in all of these cases of $a$ posteriori necessity. Take the example of the planet Venus. The names Hesperus and Phosphorus are rigid designators, i.e. they pick out their object (Venus) in all possible worlds. As such, when we discover that the two names pick out the same object in this world, it follows that they pick out the same object in every world. Thus Hesperus and Phosphorus refer to the same object necessarily. But this inference fails if we substitute definite descriptions for rigid designators. That the brightest star in the morning sky picks out the same object as the brightest star in the evening sky is true in this world, but things could certainly have been otherwise. (Likewise: the wet stuff that fills our oceans could have been something other than $\mathrm{H}_{2} \mathrm{O}$, and the third queen of England could have been born of different gametes.) This is because definite descriptions are flaccid designators; they pick out different objects in different worlds.

So without rigid designation we get no necessity. But it strikes me that names are modal concepts precisely because they are rigid designators. (It is worth noting that to illustrate the concept of rigid designation Kripke appeals to mathematical concepts, i.e. a priori necessities.) A name picks out an entity by definite description or demonstrative determination (this child, that star, etc.) and latch on to them across time and modal space. So propositions containing names are already loaded with modal content.

Kripke of course denies that names have any meaning, instead favouring a causal theory of reference. It is difficult to see how names might bear modal content without meaning. But then how they can pick out an object across modal space without modal content? I think the most plausible answer here is that names inherit their modal content from the identity of the objects they refer to, and that this identity is modal as well as diachronic, i.e. it picks out an object that persists (or extends) across worlds as well as times. In this case the question then becomes is this kind of identity a feature of the world or something we project onto it? Is object identity a cognitive or social construct?

I am inclined to say that it is. When we talk about objects (I use the term broadly to include persons, processes and anything else we might give a name to) we are dividing the world up in a particular way. But there is no limit to the alternative ways we might subdivide the universe into objects. We are naturally inclined to say that a computer and desk are two distinct objects. But this is only because it is convenient for us to do so, and there is nothing more natural about this division than one according to which they constitute a single object, or another by which the desk and key board constitute one object and the monitor and hard 
drive another. The criteria by which we distinguish particular objects are in a certain sense arbitrary; they are a consequence of our interests, not any features of the mind-independent world itself. These are the same criteria that determine a particular object's individual identity, and thereby determine their persistence across time and modal space.

There is much more to be said on this point. This argument rests on a host of assumptions about the metaphysics of object identity. But to provide a thorough defence of this claim would take us too far afield of the thesis I am trying to establish. I think I have already said more than enough to make the central point I intended to establish in this section: If one buys the widely accepted and to my mind quite plausible premise that identity is a cognitive or social construct, then the causal isolation of possibilia provides good reason for rejecting the kind of modal primitivism that would justify revisionary actualism. In the next section I will argue that this does not carry over as a reason for rejecting temporal primitivism.

\section{2: In Defence of Temporal Primitivism}

The above argument starts from the premise that we are causally isolated from the merely possible. We are therefore unable to gather empirical evidence required to justify the claim that the world bears the possibilist modes of being that the PMB primitivist posits. But we are not causally isolated from the way things were or will be, i.e. from other times. We are able to observe the world changing as time passes. Of course the modal parallel to this claim is true also: we would have been able to observe things being different had things been otherwise. But the important distinction is this: We are affected by the content of other times in such a way that justifies some of our beliefs about them. The past events, instantiation of properties etc. to which our beliefs are directed are often causally connected to our beliefs about them in an epistemically significant way. Exactly what is required for a causal connection to justify a belief is a matter for another essay. But whatever the details of a correct theory, it had better include paradigm cases of justified belief wherein a past events cause a present belief, such as my having muesli this morning causing my belief that this is the case. So we can know about other times a posteriori, and thereby know that they were different from the present and one and other. This variation between moments implies that the world is changing and change implies time. Therefore, we discover time a posteriori.

Of course the mere fact that we are able to discover tensed facts empirically does not by itself imply that tense is a feature of the world. One might discover mathematical truths 
empirically (by playing around with an abacus for example) but this doesn't mean that those conceptual truths are features of the world. It is only when coupled with the premise that we cannot discover tensed truths a priori that this inference becomes sound. Fortunately though I think this premise is true, or at least close enough to the truth. There are some tensed truths that we can discover a priori, but these are only the a priori necessities that apply to any time, e.g. I know a priori that $2+2=4$ was true yesterday and every day before and will be true tomorrow and forever after; and I know that there never were and never will be any square circles. Such necessary truths tell us nothing particular about the times themselves. So we learn about the past and (to a lesser extent) future a posteriori, i.e. by experience and only by experience. This shows us that time is a feature of the world itself, not a conceptual or cognitive construct like modality.

\section{3: An Objection from the Modality of Causation}

The core of this disanalogy between time and modality is that we are causally connected to other times but not to other worlds. If one accepts a modal analysis of causation then one may charge that this disanalogy is simply due to a failure to translate all of the modal terms into their temporal correspondents, in much the same way as Forbes' argument against the parallel discussed in section 2.2.2 fails to translate the spatiotemporal concept movement into its corresponding modal term. So if causation and by extension observation are implicitly modal terms, then we need to translate them into corresponding temporal terms when constructing parallel arguments. As far as I'm aware, there is no temporal concept in natural language that corresponds to causation, but we can construct one.

Suppose that the appropriate analysis of causation is (roughly) $p$ causes $q$ iff $\sim p \square \rightarrow \sim q$, and in turn that the appropriate analysis of a counterfactual is (again, roughly) that $p \square \rightarrow q$ iff in the nearest possible world in which $p$ obtains $q$ also obtains. Given these analyses, the claim that we cannot be affected by any posited things as they might have been amounts to a trivial tautology. There is no possible world in which $\sim p$ does not obtain at $w$. Likewise there is no time at which $p$ does not obtain at $t$. If causation is a modal term, its appropriate temporal parallel (T-causation) would be analysed in terms of a temporal parallel of counterfactuals: $p T \rightarrow q$ iff at the nearest time ${ }^{13}$ at which $p$ obtains $q$ also obtains. And so $p$

\footnotetext{
${ }^{13}$ In ordinary language we talk of nearest times we are talking about the time that is of the least temporal distance, this analysis of a nearest time does not correspond to the notion of a nearest possible world. When relating worlds, nearest means most similar. But of course we can happily
} 
T-causes $q$ iff $\sim p T \rightarrow \sim q$. Of course if $p$ is time indexed then it is always going to be true or false. But a proposition that is world indexed but not time indexed might change its truth value over time. Thus p's obtaining at w might not be able to affect us, but it can T-affect us. And this is the appropriate parallel to the claim that events at other times can affect us. So, given a modal analysis of causation, the parallel between time and modality is not undermined by the fact that we are causally connected to other times but not to other worlds.

Or so one might argue. But even if it is conceded that there is a temporal correspondent to causation that should take its place in arguments concerning modality, the parallel between time and modality soon breaks down once again. This T-causation has little bearing on matters of justification, or epistemology in general. Our causal connectedness to other times enables us to justify our belief that they are features of the world itself. But T-causation lacks the epistemic significance of its modal counterpart. Mere T-causal relatedness does not enable justified beliefs about the content of merely possible worlds from which we are causally isolated. So the fact that we cannot be affected by mere possibilities may turn out to be a tautology, but not a trivial one.

stipulate that in this case what we mean by nearest time is the most similar time. And in the vast majority of cases the two analyses will overlap extensionally. 


\section{Summary}

So this difference in causal relatedness is the core of the disanalogy between time and modality that truthmaking shows up. We can plausibly posit ontologically primitive temporal modes of being because we are causally connected to other times in such a way that we can garner empirical evidence for them. Moreover, presentists should adopt this brand of temporal primitivism because it is the only position that is compatible with the thesis that time is ontologically prior to existence, and this thesis is necessary for a plausible presentist account of change. Given this temporal primitivism, the presentist is justified in rejecting the demand for existing truthmakers as question begging, because her conception of reality comprises more than just what exists. Instead she can revise the truthmaking principle to allow for truthmakers that did or will exist.

In contrast, the actualist is unable to justify a revisionary approach in the same way because it is epistemically implausible for her to posit ontologically primitive possibilist modes of being. If there were entities in such modes of being, they would be causally isolated from, and thus empirically inaccessible to us. So we could not, even in principle, gather evidence for them and thus cannot be justified in positing them.

Thus we have an independent reason to retain presentism in the face of the truthmaking challenge that does not carry over as a defence of actualism. Of course this doesn't necessarily mean that actualists cannot provide an adequate rebuttal of the truthmaking challenge. But if they can their justification will not parallel the justification the presentist appeals to. So one might rationally accept one defence and not the other, and so we are freed of the commitment to ontological symmetry that the world-time parallel had thrust upon us. 


\section{$\underline{\text { References }}$}

Adams, R.M. (1974). Theories of Actuality. Noûs. Vol. 8: 211-231.

Armstrong, D.M. (1983). What is a Law of Nature? Cambridge: Cambridge University Press.

Armstrong, D.M. (1989). A Combinatorial Theory of Possibility. Cambridge: Cambridge University Press.

Armstrong, D.M. (2004). Truth and Truthmakers. Cambridge: Cambridge University Press.

Ayer, A.J. (1936). Language, Truth and Logic. London: Victor Gollancz Ltd., 1946. Second edition.

Bigelow, J. (1988). The Reality of Numbers: A Physicalist's Philosophy of Mathematics. Oxford: Oxford University Press.

Bigelow, J. (1996). Presentism and Properties. Noûs, Vol. 30, Supplement: Philosophical Perspectives, 10, Metaphysics: 35-52.

Bourne, C. (2006) A Future for Presentism. Oxford: Oxford University Press.

Brady, R. (2004). On the Formalization of the Law of Non-Contradiction, in The Law of NonContradiction. In G. Priest, J. C. Beall, and B. Armour-Garb (eds.), New Philosophical Essays. Oxford: Clarendon Press.

Broad, C.D. (1923). Scientific Thought, London: Kegan Paul.

Cameron, R.P. (2008). Comments on Merricks's Truth and Ontology. Philosophical Books. Vol. 49, 4: 292-301.

Cameron, R. P. (2009). What's Metaphysical about Metaphysical Necessity? Philosophy and Phenomenological Research, Vol. 79: 1-16.

Cameron, R. P. (2011). Truthmaking for Presentists. Oxford studies in metaphysics. Oxford: Oxford University Press.

Cresswell, M. J. (1990). Modality and Mellor's McTaggart. Studia Logica: An International Journal for Symbolic Logic , Vol. 49, 2: 163-170.

Crisp, T.M. (2003) Presentism. In M. Loux and D. Zimmerman (eds.), The Oxford Handbook of Metaphysics. Oxford: Oxford University Press, 211-45.

Crisp, T.M. (2007). Presentism and the Grounding Objection. Noûs, Vol. 41, 1: 90-109.

Davidson, M. (2003). Presentism and the Non-Present. Philosophical Studies Vol. 113: 7792.

Forbes, G. (Jun., 1983). Actuality and Context Dependence I. Analysis, Vol. 43, 3: 123-128.

Gallois, A. (2004) Comments on Ted Sider: Four Dimensionalism: An Ontology of Persistence and Time. Philosophy and Phenomenological Research , Vol. 68, 3: 648-657. 
Heathwood, C. (2007). On What Will Be: reply to Westphal. Erkenntnis. Vol. 67: 137-142.

Hintikka, J. (1962). Knowledge and Belief. Cornell University Press: Ithaca, NY.

Keller, S. (2004). Presentism and Truthmaking. Oxford Studies in Metaphysics. Vol. 1: 83106.

Kripke, S. (1963). Semantical Analysis of Modal Logic. Zeitschrift für Mathematische Logik und Grundlagen der Mathematik, Vol. 9: 67-96.

Kripke, S.A. (1972). Naming and Necessity. In D. Davidson and G. Harman (eds.) Semantics of Natural Language. (Dordrecht: D. Reidel Publishing Company, 1972).

Lewis, D.K. (1973). Counterfactuals. Cambridge, Mass.: Harvard University Press.

Lewis, D.K. (1986). On the Plurality of Worlds. Oxford: Blackwell.

Markosian, Ned (2001). Critical Study of R. Le Poidevin (ed.) Questions of Time and Tense. Oxford: Oxford University Press, 1998. Noûs. Vol. 35, 4: 616-629.

McTaggart, J.M.E. (1908). The Unreality of Time, Mind. Vol. 17: 457-474.

Mellor, D. H. (1981). Real Time. Cambridge University Press.

Mellor D. H. (2003). Real Metaphysics: Replies. In H. Lillehammer \& G. Rodriguez-Pereyra (eds.), Real Metaphysics. London: Routledge: 212-238.

Merricks, T. (2007). Truth and Ontology. Oxford University Press, USA.

Parsons, J. (2005). Truthmakers, the Past, and the Future. In H. Beebee \& J. Dodd (eds.), Truthmakers: The Contemporary Debate. Clarendon.

Parsons, J. (2004). Distributional Properties. In Frank Jackson and Graham Priest (eds.), Lewisian Themes, 173-80. Oxford: Oxford University Press.

Prior, A. (1967). Past, Present and Future. Oxford: Clarendon Press.

Quine, W. V. (1936). Truth by Convention. In his Ways of Paradox and Other Essays, 1976. 2nd ed., Cambridge, MA: Harvard University Press.

Quine, W. (1956), Carnap and Logical Truth. In his Ways of Paradox and Other Essays, 1976. 2nd ed., Cambridge, MA: Harvard University Press.

Read, S. (2001). Truthmakers, entailment and necessity. In Heinrich Wansing (eds.), Essays on Nonclassical Logic. Singapore: World Scientific.

Restall, G. (1996). Truthmakers, Entailment and Necessity. Australasian Journal of Philosophy. Vol. 74: 331-340.

Rosen, G. (1990). Modal Fictionalism. Mind. Vol. 99: 327-354.

Ryle, G. (1949). The Concept of Mind. London: Hutchinson. 
Sanson and Caplan (2010) The Way Things Were. Philosophy and Phenomenological Research. Vol. 81, 1: 24-39.

Sider, T. (2001). Four Dimensionalism: An Ontology of Persistence and Time. Oxford: Oxford University Press.

Sider, T. (2003). Reductive Theories of Modality. In M. Loux and D. Zimmerman (eds.), The Oxford Handbook of Metaphysics. Oxford: Oxford University Press: 180-208.

Sider, T. (2004) Replies to Gallois, Hirsch and Markosian. Philosophy and Phenomenological Research. Vol. 68, 3: 674-687

Tallant, J. (2009). Ontological Cheats Might Just Prosper. Analysis. Vol. 69, 3: 422-430.

Tallant, J. (2010). Still Cheating, Still Prospering. Analysis. Vol. 70, 3: 502-506.

Tooley, M. (1997). Time, Tense, and Causation. Oxford: Oxford University Press.

Torrengo (2011). The Grounding Problem and Presentist Explanations. Forthcoming, Synthese. http://www.springerlink.com/content/5384212230312001

Westphal, J. (2006). The Future and the Truth-Value Links: a Common Sense View. Analysis, Vol. 66: 1-9. 